\title{
Marine regime shifts in ocean biogeochemical models: a case study in the Gulf of Alaska
}

\author{
Claudie Beaulieu ${ }^{1}$, Harriet Cole ${ }^{1, \mathrm{a}}$, Stephanie Henson ${ }^{2}$, Andrew Yool $^{2}$, Thomas R. Anderson ${ }^{2}$, Lee de Mora ${ }^{3}$, \\ Erik T. Buitenhuis ${ }^{4}$, Momme Butenschön ${ }^{3}$, Ian J. Totterdell ${ }^{5}$, and J. Icarus Allen ${ }^{3}$ \\ ${ }^{1}$ Ocean and Earth Science, University of Southampton, Southampton, UK \\ ${ }^{2}$ National Oceanography Centre, Southampton, UK \\ ${ }^{3}$ Plymouth Marine Laboratory, Plymouth, UK \\ ${ }^{4}$ Tyndall Centre for Climate Change research, School of Environmental Sciences, University of East Anglia, \\ Norwich, UK \\ ${ }^{5}$ Hadley Centre, Met Office, Exeter, UK \\ ${ }^{a}$ now at: MSS Marine Laboratory, Marine Scotland Science, Aberdeen, UK
}

Correspondence to: C. Beaulieu (c.beaulieu@soton.ac.uk)

Received: 23 June 2015 - Published in Biogeosciences Discuss.: 26 August 2015

Revised: 23 March 2016 - Accepted: 14 June 2016 - Published: 12 August 2016

\begin{abstract}
Regime shifts have been reported in many marine ecosystems, and are often expressed as an abrupt change occurring in multiple physical and biological components of the system. In the Gulf of Alaska, a regime shift in the late 1970 s was observed, indicated by an abrupt increase in sea surface temperature and major shifts in the catch of many fish species. A thorough understanding of the extent and mechanisms leading to such regime shifts is challenged by data paucity in time and space. We investigate the ability of a suite of ocean biogeochemistry models of varying complexity to simulate regime shifts in the Gulf of Alaska by examining the presence of abrupt changes in time series of physical variables (sea surface temperature and mixed-layer depth), nutrients and biological variables (chlorophyll, primary productivity and plankton biomass) using change-point analysis. Our results show that some ocean biogeochemical models are capable of simulating the late 1970s shift, manifested as an abrupt increase in sea surface temperature followed by an abrupt decrease in nutrients and biological productivity. Models from low to intermediate complexity simulate an abrupt transition in the late 1970s (i.e. a significant shift from one year to the next) while the transition is smoother in higher complexity models. Our study demonstrates that ocean biogeochemical models can successfully simulate regime shifts in the Gulf of Alaska region. These models can therefore be considered useful tools to enhance
\end{abstract}

our understanding of how changes in physical conditions are propagated from lower to upper trophic levels.

\section{Introduction}

Although there is no universal definition of a marine regime shift, they are typically described as an abrupt change in the ecosystem from one state to another, which is detectable in multiple physical and biological components of the system (Lees et al., 2006; Daskalov et al., 2007; deYoung et al., 2008; Andersen et al., 2009; Schwing, 2009). Generally, the magnitude of the regime shift is large and it occurs rapidly relative to the time spent in the different states (e.g. a shift from one year to the next that persists on decadal or longer timescales). The regime shift can be a linear response to an abrupt change in forcing (e.g. climate shift), a nonlinear response to a small change in forcing or driven by the internal dynamics of the system (Andersen et al., 2009; Bestelmeyer et al., 2011), but the exact mechanisms are often unknown.

Key drivers of marine regime shifts include changes in ecosystem habitat, biotic processes such as dynamics of the foodweb and abiotic processes such as changes in physical and chemical conditions (deYoung et al., 2008). These drivers can be natural or anthropogenic, or a combined influence, which can increase the vulnerability of ecosystems 
(e.g. an ecosystem which has less resilience due to increasing human pressure tends to respond differently to an ecosystem subject only to natural disturbances; Folke et al., 2004). Excessive fishing is an example of an anthropogenic biotic driver where a decrease in top predators (top-down control) can cause a trophic cascade, resulting in a new bottomup controlled state (Daskalov et al., 2007). Abiotic factors such as climate change or ocean and atmosphere oscillations may initiate bottom-up regime shifts in the food web via changes affecting the abundance of phytoplankton or zooplankton (Cury and Shannon, 2004). Typically, bottom-up driven shifts in biological components of the ecosystem generated by climate shifts manifested in changes in sea surface temperature or mixed-layer depth are considered the most easily identified (deYoung et al., 2008) and are the focus of this study.

Temporal and spatial scales of regime shifts may also affect their detectability (e.g. from a small scale coral reef regime shift occurring within a single year to a North Pacificwide ecosystem regime shift taking a few years to transition; Drinkwater, 2006; deYoung et al., 2008). Hence, detection of a shift in a large complex marine ecosystem such as the North Pacific or North Atlantic, in which there may be lags between the expression of the shift in the abiotic and biotic components of the system, may be more difficult than detecting a regime shift in a small coral reef (deYoung et al., 2008).

Regime shifts associated with changes in physical conditions have been previously reported in the North Atlantic (Drinkwater, 2006; Beaugrand et al., 2009; Alheit et al., 2014), North Sea (Reid et al., 2001; Beaugrand, 2004; McQuatters-Gollop et al., 2007) and North Pacific (Polovina et al., 1995; Mantua et al., 1997; Hare and Mantua, 2000; Litzow and Mueter, 2014), among others. The late 1970s North Pacific regime shift has been comprehensively studied (Mantua et al., 1997; McGowan et al., 1998; Francis et al., 1998; Hare and Mantua, 2000; Yatsu et al., 2008). It was observed in a composite time series of 100 physical and biological variables, which revealed an abrupt and sustained change during 1976/77 (Hare and Mantua, 2000). At that time, there was a deepening of the Aleutian low-pressure system which doubled the eastward wind stress and brought cooler winds over the central North Pacific, causing a drop in sea surface temperature (SST) and a deepening of the mixedlayer depth (MLD). This resulted in moister and warmer air settling over the California Current region and the Gulf of Alaska, which caused an increase in SST in these two regions (Mantua et al., 1997). This mechanism has been described as the Pacific Decadal Oscillation (PDO), which switched from a negative to a positive state in 1976/77 (Mantua et al., 1997). The late 1970s shift is thereby implicitly related to El Niño Southern Oscillation (ENSO) variability, whose shorter timescale fluctuations combined with random atmospheric forcing enforce decadal variability in the PDO (Newman et al., 2003). Alternatively, other large-scale climate pat- terns such as the North Pacific Gyre Oscillation (NPGO) may impact on marine ecosystem dynamics. Concurrent with the switch in the PDO state, an increase in zooplankton biomass was observed in the Gulf of Alaska between the periods of 1956-1962 and 1980-1989 (Brodeur and Ware, 1992). In upper trophic levels, abrupt increases in groundfish recruitment and salmon catches were observed, while some forage fish populations collapsed with consequences for piscivorous sea birds and marine mammal populations (Anderson and Piatt, 1999). Overall the yield of fish stocks in the Gulf of Alaska increased from the 1970s to the 1990s (McGowan et al., 1998).

Although a climate shift occurred over the entire North Pacific, the ecological response varied between regions depending on their respective dominant processes (Schwing, 2009). For example, in the California Current region the ecological changes associated with the 1977 climate shift were different from those that occurred in the Gulf of Alaska with lower salmon catches after 1977 (Mantua et al., 1997). Investigation of the magnitude and extent of the regime shift and the proposed mechanism is challenged by the paucity of data covering adequate time and space scales in the Gulf of Alaska. Most support for the observed biological changes comes from fisheries stock assessments, which are not designed to study how climate shifts are affecting marine ecosystems (McGowan et al., 1998). A few modelling studies have attempted to simulate the chain of events for the late 1970s shift, but the direction of changes in the simulations of the physical and biological parameters are sometimes opposite, and also vary according to the space/timescale of the study (e.g. Polovina et al., 1995; Haigh et al., 2001; Capotondi et al., 2005; Alexander et al., 2008). By using the late 1970s regime shifts in the Gulf of Alaska as a case study we aim to assess the ability of five global ocean biogeochemical models to simulate this shift. The models were part of the UK Integrated Global Biogeochemical Modelling Network (iMarNet) intercomparison, which aimed to evaluate the models' ability to simulate global-scale bulk biogeochemical properties using the same ocean general circulation model and atmospheric forcing (Kwiatkowski et al., 2014). These physically identical hindcast simulations allow any model differences to be ascribed only to their representation of biogeochemical processes, thereby providing insight into the mechanisms leading to marine regime shifts.

A substantial part of the literature on regime shifts uses principal component analysis to compress a large number of time series representing the state of the ecosystem to a smaller number of uncorrelated ones, which indicates to what extent the different components of the system are responding coherently. For example, Hare and Mantua (2000) reduced a total of 100 time series of physical and biological variables representing the state of the North Pacific to two leading modes of variability. The presence of regime shifts in the reduced set of time series may render the presence of shifts more evident to visual inspection, but this is often 
done without further significance testing (Andersen et al., 2009). In order to objectively identify the timing of a shift and distinguish it from a random fluctuation, change-point techniques can be used, especially methods designed to detect multiple shifts in the mean of a time series (e.g. Andersen et al., 2009). For example, the shift detection methodology proposed by Rodionov (2004) consists of applying a t-test successively to compare the means of two segments of a time series, considering all possible timings for a shift, and repeats this until all shifts have been detected. This method has been applied widely in the marine regime shift literature (e.g. Daskalov et al., 2007; DeYoung et al., 2008; Overland et al., 2008, 2010; Yatsu et al., 2008; Möllmann et al., 2009). However, it is not designed to distinguish a shift from a trend, which may lead to the detection of a series of spurious shifts in the presence of a background long-term trend (e.g. Spencer et al., 2011). Furthermore, it may lead to the detection of spurious shifts in the presence of red noise, which creates patterns that may be interpreted as shifts, but which are purely random (e.g. Wunsch, 1999; Rudnick and Davis, 2003). Red noise is often present in biological time series such as chlorophyll (e.g. Beaulieu et al., 2013) or plankton abundance (e.g. Di Lorenzo and Ohman, 2013), and manifests through a slow integrated response to random weather forcings (Di Lorenzo and Ohman, 2013). Therefore, we opt for a methodology capable of separating a long-term trend from an abrupt change signal (e.g. which occurs from one year to the next) and distinguishing these signals from red noise (Beaulieu et al., 2012). In order to provide further insights as to whether the shifts detected are a linear response to a shift in the forcing itself (e.g. climate shift) from shifts generated through a nonlinear response of some change in the forcing, also called thresholds or "tipping points" (Scheffer et al., 2009), the relationship between the forcing and the response was explored using regression models (Bestelmeyer et al., 2011).

Our analysis is organized as follows. First, we investigate whether shifts are present in the Gulf of Alaska as predicted in a multiple model intercomparison hindcast experiment, iMarNet (Kwiatkowski et al., 2014; www.imarnet.org). Specifically, we analyse model physical and biological variables for regime shifts and verify whether these shifts are internally coherent. Then, we investigate the contribution of the different physical and biological variables to the observed late 1970s and late 1980s shifts in the Gulf of Alaska and the type of forcing-response relationship that led to abrupt changes.

\section{Methodology}

\subsection{Ocean biogeochemical models}

This study uses ocean biogeochemistry model (OBGC) outputs from the iMarNet intercomparison project. The pri- mary aim of iMarNet was to investigate the model complexity required to adequately represent marine ecosystems (Kwiatkowski et al., 2014). The participating models were HadOCC (Palmer and Totterdell, 2001), Diat-HadOCC (Halloran et al., 2010), MEDUSA-2 (Yool et al., 2011, 2013), PlankTOM10 (Le Quéré et al., 2005) and ERSEM (Baretta et al., 1995; Blackford et al., 2004). These models cover a large span of model complexity from 7 state variables (including 2 plankton functional types; PFTs) in HadOCC through to 57 state variables (including 8 PFTs) in ERSEM. The hindcast simulations (covering the period 1957 to 2007) from each of the models were used in this study.

The key focus of the iMarNet intercomparison was to evaluate the models' ability to simulate global-scale bulk properties, such as carbon and nutrient cycles, as a representation of marine biotic activity (Kwiatkowski et al., 2014). The different OBGC models were implemented within a common physical framework to eliminate confounding differences due to the physics that would otherwise occur if different physical models were involved. This framework used the Nucleus for European Modelling of the Ocean (NEMO) physical ocean general circulation model (Madec, 2008) coupled to the Los Alamos sea-ice model (CICE; Hunke and Lipscomb, 2008), with surface atmospheric forcing drawn from the common ocean-ice reference experiment (CORE2; Large and Yeager, 2009). The model grid was configured at approximately $1^{\circ}$ horizontal resolution, with 75 vertical levels increasing in thickness from $1 \mathrm{~m}$ at the surface to 200 at $6000 \mathrm{~m}$ depth.

The models were initialized from an identical physical state in 1890 using the same 3-D biogeochemical tracer fields (although not all of these tracers were used in every model). Macronutrients (nitrate, phosphorus, silicic acid) and dissolved oxygen initial condition fields were drawn from the World Ocean Atlas 2009 (Garcia et al., 2010a, b), while fields of dissolved inorganic carbon and alkalinity were drawn from the Global Ocean Data Analysis Project (GLODAP) database (Key et al., 2004). Each model used its own source for iron fields as currently there is no comprehensive global dataset available. The remaining fields such as plankton and particulate and dissolved organic matter were initialized with arbitrary small initial conditions. Below is a brief description of the structure of each OBGC model, which is also summarized in Table 1. Additional details can be found in Kwiatkowski et al. (2014).

- The Hadley Centre Ocean Carbon Cycle (HadOCC) model is a simple NPZD (Nutrient, Phytoplankton, Zooplankton, Detritus) model consisting of one phytoplankton group and one zooplankton group. There is one nutrient pool, nitrogen, to which the cycling of carbon and alkalinity is coupled. Further details can be found in Palmer and Totterdell (2001).

- Diat-HadOCC is a descendant of HadOCC with the primary difference being the presence of two phytoplank- 
Table 1. Nutrient cycles and Plankton Functional Types represented in each model.

\begin{tabular}{|c|c|c|c|c|c|c|}
\hline & & HadOCC & Diat-HadOCC & MEDUSA & PlankTOM10 & ERSEM \\
\hline \multirow{6}{*}{ Nutrients } & Nitrogen & $\mathrm{x}$ & $\mathrm{x}$ & $\mathrm{x}$ & $\mathrm{x}$ & $\mathrm{x}$ \\
\hline & Phosphorous & & & & $\mathrm{x}$ & $\mathrm{x}$ \\
\hline & Silica & & $\mathrm{x}$ & $\mathrm{x}$ & $\mathrm{x}$ & $\mathrm{x}$ \\
\hline & Iron & & $\mathrm{x}$ & $\mathrm{x}$ & $\mathrm{x}$ & $\mathrm{x}$ \\
\hline & Carbon & $\mathrm{x}$ & $\mathrm{x}$ & $\mathrm{x}$ & $\mathrm{x}$ & $\mathrm{x}$ \\
\hline & Alkalinity & $\mathrm{x}$ & $\mathrm{x}$ & $\mathrm{x}$ & $\mathrm{x}$ & $\mathrm{x}$ \\
\hline \multirow{15}{*}{$\begin{array}{l}\text { Plankton } \\
\text { functional type }\end{array}$} & Generic phytoplankton & $\mathrm{x}$ & $\mathrm{x}$ & & $\mathrm{x}$ & \\
\hline & Diatoms & & $\mathrm{x}$ & $\mathrm{x}$ & $\mathrm{x}$ & $\mathrm{x}$ \\
\hline & Large phytoplankton & & & & & $\mathrm{x}$ \\
\hline & Picoplankton & & & $\mathrm{x}$ & $\mathrm{x}$ & $\mathrm{x}$ \\
\hline & Coccolithophores & & & & $\mathrm{x}$ & \\
\hline & $\mathrm{N}_{2}$ fixers & & & & $\mathrm{x}$ & \\
\hline & Flagellates & & & & & $\mathrm{x}$ \\
\hline & Phaeocystis & & & & $\mathrm{x}$ & \\
\hline & Generic zooplankton & $\mathrm{x}$ & $\mathrm{x}$ & & & \\
\hline & Microzooplankton & & & $\mathrm{x}$ & $\mathrm{x}$ & $\mathrm{x}$ \\
\hline & Mesozooplankton & & & $\mathrm{x}$ & $\mathrm{x}$ & $\mathrm{x}$ \\
\hline & Macrozooplankton & & & & $\mathrm{x}$ & \\
\hline & Heterotrophic nanoflagellates & & & & & $\mathrm{x}$ \\
\hline & Bacteria & & & & $\mathrm{x}$ & $\mathrm{x}$ \\
\hline & Tracers & 7 & 13 & 15 & 39 & 57 \\
\hline
\end{tabular}

ton groups: diatoms and mixed phytoplankton. Further differences include the addition of the nutrients silica and iron and the effect of nutrient limitation on growth is multiplicative, where light limitation is multiplied by successive nutrient limitation terms. Further details can be found in Halloran et al. (2010).

- Model of Ecosystem Dynamics, nutrient Utilization, Sequestration and Acidification (MEDUSA) is an intermediate complexity model comprising two phytoplankton and two zooplankton groups. The ecosystem is split into small (nanophytoplankton and microzooplankton) and large (diatom and mesozooplankton) components, and non-living detrital material is similarly split to reflect its sources. Nutrient pools included in this model are nitrogen, silica and iron and the effect of nutrient limitation on growth is also multiplicative. Cycles of carbon, alkalinity and dissolved oxygen are also included. Further details can be found in Yool et al. (2011) and Yool et al. (2013).

- PlankTOM10 is a relatively complex model and has 10 PFTs (diatoms, coccolithophores, Phaeocystis, nitrogen fixers, picophytoplankton, mixed phytoplankton, protozoa, mesozooplankton, macrozooplankton and bacteria). The nutrient cycles included in PlankTOM10 are carbon, nitrogen, oxygen, phosphorous, silica and a simplified iron cycle. Phytoplankton growth is regulated by the minimum of nutrient limitation terms. All zooplankton groups eat smaller PFTs, with preference based on size. Further details can be found in Le Quéré et al. (2005) and Buitenhuis et al. (2013).

- The European Regional Seas Ecosystem Model (ERSEM) was originally used for shelf seas and consists of both pelagic and benthic ecosystems. Four phytoplankton groups (picophytoplankton/flagellates, flagellates, large phytoplankton and diatoms), three zooplankton groups (heterotrophic flagellates, microzooplankton and mesozooplankton) and heterotrophic bacteria are represented. Each zooplankton group grazes on a preferred phytoplankton group or groups based on size. The nutrient pools consist of carbon, nitrogen, phosphorous, silica and dissolved oxygen allowing for dynamic stoichiometric internal quotas. The effect of nutrient limitation on growth is a combination of multiplicative and maximum limitation factors. More details can be found in Blackford (1997), Blackford et al. (2004) and Butenschön et al. (2016).

\subsection{Simulation}

For each biogeochemical model, conventional simulations from the same physical initial state were performed identically from year 1890 through to 2007 . For the first 60 years of these simulations (1890-1949 inclusive), CORE2 (Common Ocean-ice Reference Experiments, version 2; Large and Yeager, 2009) seasonal climatology (i.e. without interannual variability) was used, the so-called "normal year forcing". Subsequently (1950-2007 inclusive), interannually 
varying CORE2 forcing was used to complete the simulations. CORE2 provides observationally derived geographical fields of downwelling irradiance (short- and long-wave), precipitation (rain and snow), air temperature, humidity, and meridional and zonal winds. These are used in conjunction with bulk formulae to calculate net heat, freshwater and momentum exchange between the atmosphere and the ocean. In addition, sea surface salinity was weakly relaxed (characteristic timescale of 180 days) towards observations to minimize drift. Note that the simulations were "online", in that physics and biogeochemistry were both formally simulated simultaneously. Feedbacks between the model biology and ocean physics (e.g. by the absorption of downwelling solar radiation) were disabled so that all of the biogeochemical models experienced consistent simulated physics. Additional details on the simulations can be found in Kwiatkowski et al. (2014).

For each model, where available, time series of sea surface temperature (SST), mixed-layer depth (MLD, defined as a density difference from the surface of $0.1 \mathrm{~kg} \mathrm{~m}^{-3}$ ), surface dissolved inorganic nitrogen (DIN), silica (SI), iron (FE), surface chlorophyll (CHL), integrated primary production (PP), total surface phytoplankton (PHY) and zooplankton (ZOO) biomass were extracted from 1957 to 2007 (same period as the observational dataset used, see section below) for the Gulf of Alaska region. The time series were averaged from monthly means to annual means and then averaged spatially across the region defined by the boundaries of 54 to $62^{\circ} \mathrm{N}$ and 130 to $160^{\circ} \mathrm{W}$ (same region as the observational dataset used, see section below).

\subsection{Observational dataset}

To compare shifts found in model time series to observed ones, SST data were extracted from the Extended Reconstructed Sea Surface Temperature (ERSST) dataset (version 3b) downloaded from https://www.ncdc.noaa.gov/ersst/. This analysis uses the International Comprehensive OceanAtmosphere Data Set SST data and combines ship and buoy data (Smith and Reynolds, 2003; Smith et al., 2008). The data were available as monthly means with a spatial resolution of $2^{\circ} \times 2^{\circ}$ from 1957 to 2007 . The ERSST dataset was averaged spatially for each year over the Gulf of Alaska to form a time series of annual mean SST. Comparison with observed time series for other variables (i.e. MLD, DIN, SI, FE, CHL, PP, PHY, ZOO) is not possible due to lack of data over suitable space and timescales. Time series of large-scale oscillations representing the climate over the North Pacific were obtained. The PDO index (Mantua et al., 1997) was downloaded from http://www.atmos. washington.edu/ mantua/abst.PDO.html. The Multivariate ENSO Index (MEI; Wolter and Timlin, 1998) was downloaded from http://www.esrl.noaa.gov/psd/enso/mei/ and the NPGO index (DiLorenzo et al., 2008) was downloaded from http://www.o3d.org/npgo/npgo.php. Annual time series of
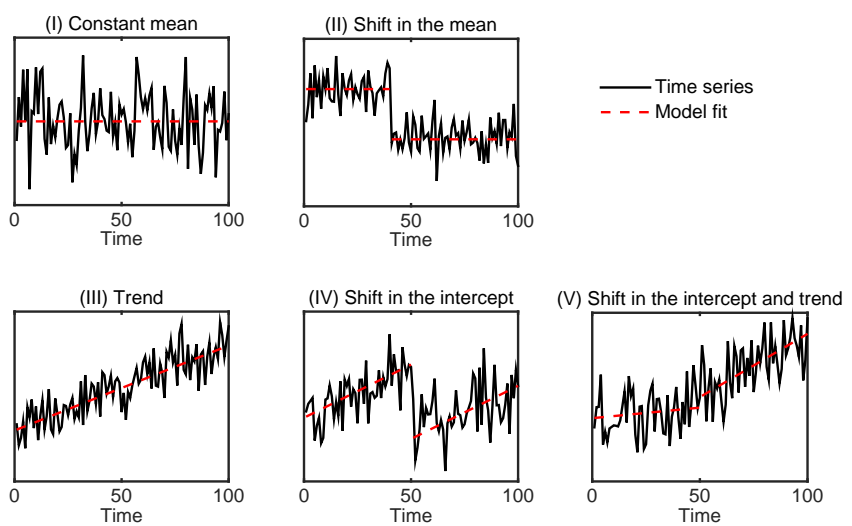

Figure 1. Five types of statistical models that were fitted to the data. The solid lines are synthetic time series drawn from a model with (I) a constant mean, (II) shift in the mean, (III) trend, (IV) shift in the intercept of the trend (the trend is the same before and after the shift) and (V) shift in both the intercept and trend. The constant mean (I) is the null model for a shift in the mean (II) when testing for significance. Similarly, the trend model (III) is the null model to test the shift significance when the model selected is either a shift in the intercept (IV) or a shift in both the intercept and trend (V). The corresponding models are further described in Table 2. Figure adapted from Beaulieu et al. (2012).

PDO, ENSO and NPGO indices were produced by averaging monthly time series.

\subsection{Statistical analyses}

For the regime shift detection, we use the change-point detection method presented in Beaulieu et al. (2012), which distinguishes shifts in a time series from long-term trends and red noise. It consists of fitting a suite of regression models to a time series with (I) constant mean, (II) shift in the mean, (III) trend, (IV) shift in the intercept of the trend and (V) shift in both the intercept and trend, and discriminates between them. Figure 1 illustrates the five regression models tested in this study and their equations are presented in Table 2. This methodology is based on the Schwarz Information Criterion (SIC), which is a measure of goodness of fit based on the maximum likelihood function of a given model penalized by the number of parameters estimated to ensure balance between good fit and parsimony. We use the SIC to (1) identify the timing of the shift under a model formulation containing a shift and (2) determine which regression model (among the five fitted) provides the best fit. The SIC formulations for the five models are presented in Table 2. For the models with a shift (II, IV, V), the SIC is calculated for each possible timing of a shift - the timing with the lowest SIC corresponds to the year that the shift is most likely to have occurred. The search for the most likely timing for a shift excludes the first and last five data points in the time series to avoid spurious detection (Beaulieu et al., 2012). For example, the most likely timing 
for a shift for model II would be

$\operatorname{SIC}_{\mathrm{II}}(p)=\min \left\{\operatorname{SIC}_{\mathrm{II}}(k), k=5, \ldots, n-5\right\}$.

The most likely timing for a shift under models IV and V can be found similarly, and are denoted $\operatorname{SIC}_{\mathrm{IV}}(p)$ and $\operatorname{SIC}_{\mathrm{V}}(p)$, respectively.

Once the SIC of the five models are computed, the smallest one is selected as the most appropriate to represent the time series (Table 2). If the SIC of a model without a shift (constant mean (I) or trend (III)) is lower than the SIC of the models with a shift (shift in the mean (II), shift in the intercept (IV) or shift in the intercept and trend (V)), no abrupt change is detected in that time series. On the other hand, if a model with a shift has the smallest SIC, this indicates that there could be a shift in that time series.

There is no significance level involved with the decision rule presented above and shifts tend to be too easily detected (Beaulieu et al., 2012). Therefore, a critical value can be added to the decision rule to assess the significance of the shift based on the difference in SIC between the shift model and the null model and is determined using Monte Carlo simulations. For example, if model II is selected with the smallest SIC, the null model to compare with is model I. The shift detected in model II will be significant if

$\operatorname{SIC}_{\mathrm{II}}(p)-\mathrm{SIC}_{\mathrm{I}}<c_{\alpha}$,

where $c_{\alpha}$ is the critical value at the $\alpha$ critical level and is determined by Monte Carlo simulation. Similarly, when models IV or V have the smallest SIC, the shift will be significant if

$\operatorname{SIC}_{\mathrm{IV}}(p)-\mathrm{SIC}_{\mathrm{III}}<c_{\alpha}$

or

$\operatorname{SIC}_{\mathrm{V}}(p)-\mathrm{SIC}_{\mathrm{III}}<c_{\alpha}$

We generate 1000 synthetic time series randomly drawn from a normal distribution with the same length (i.e. number of years), variance and first-order autocorrelation (if present) as the data. The presence of autocorrelation usually indicates the presence of external factors not accounted for in the model and the AR(1) should act as a parameter which roughly comprises these factors. The SIC differences between the model with a shift (e.g. model II) and the corresponding null model (e.g. model I) are calculated. This produces a null distribution for $c_{\alpha}$ against which the observed SIC difference is compared to estimate the $p$ value. The $p$ value here is the probability of observing an SIC difference at least as extreme as that observed under the null hypothesis of no shift in the time series. We use a $5 \%$ critical level, i.e. we reject the null hypothesis of no shift if the $p$ value is smaller than 0.05. This analysis is based on the assumption that the residuals of the selected model are normally distributed with a constant variance, which is verified using a Lilliefors test and Fisher test (5\% critical level). Violation of these assumptions could indicate the presence of additional shifts in the time series.

This method is flexible and allows for the detection of shifts that are more complex than simply a shift in the mean. Furthermore, it distinguishes potential shifts from red noise, which is important given the background climate change trend and long memory of the climate system (characterized as high first-order autocorrelation). However, this method can detect at most one shift in the time series, while there could possibly be multiple shifts over a multidecadal time period. Therefore, the shift identified will be the largest to occur in a time series, which for the Gulf of Alaska is expected to be the 1977 regime shift.

To unveil shifts in SST in and around the Gulf of Alaska, we first apply this methodology to observed annual SST time series over the North Pacific (from 40-70 ${ }^{\circ} \mathrm{N}$ and 180 $\left.120^{\circ} \mathrm{W}\right)$. Second, we apply this methodology to time series of physical and biological variables simulated from each of the five ocean biogeochemical models, and to observed SST, averaged over the Gulf of Alaska as described in Sects. 2.1 and 2.2 respectively. As a visual aid, we also calculate cumulative sums of the $z$ scores of each time series. Cumulative sums are useful for monitoring time series as they exhibit a change of slope when a shift in the time series occurs (e.g. Page, 1954).

We apply principal component analysis to the $z$ scores of the physical and biological time series averaged over the Gulf of Alaska for each model to reduce the dimensions of all variables analysed here into uncorrelated principal components. We also apply the change-point methodology to the first principal component (PC1) obtained for each model, which explains most of the variability, and test whether PC1 also exhibits a shift in the late 1970s. We then investigate which variables are contributing most to the late 1970s shift, by comparing their individual contributions to PC1 for each model.

We further investigate the physical forcing - biological response relationship in models that simulate a significant shift in the late 1970s in PC1. We investigate the presence of changes in physical-biological relationships before and after the shift by comparing the regression slopes, following the approach proposed by Bestelmeyer et al. (2011). Similar slopes before and after the shift could indicate a linear response to the physical forcing, while a change in the slopes might rather suggest a change in the relationship and thus, a nonlinear response. More specifically, we fit simple linear regression models, such as

$y_{t}=a_{1}+b_{1} x_{t}+e_{t} \quad t=1, \ldots, p$

$y_{t}=a_{2}+b_{2} x_{t}+e_{t} t=p+1, \ldots, n$,

where $y_{t}$ represents the biological response (either CHL, PP, PHY or ZOO), $x_{t}$ is the physical forcing (either SST or MLD), $a_{1}$ and $b_{1}$ are the intercept and regression slope before the shift at time $p, a_{2}$ and $b_{2}$ are the intercept and regres- 
Table 2. List of models fitted in this study with their associated Schwarz Information Criterion (SIC) formulation.

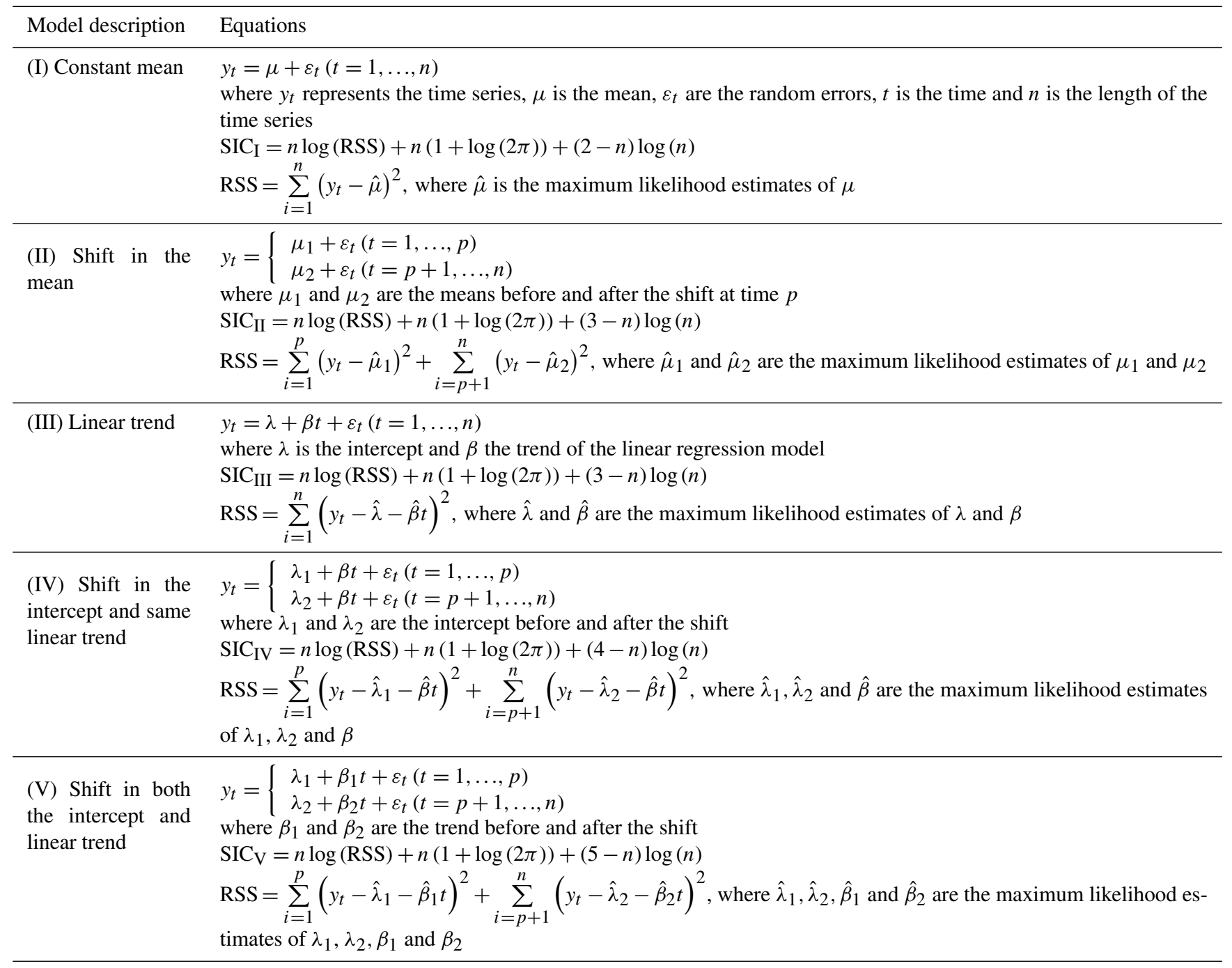

* All these models rely on the assumption that the random errors are independent and identically normally distributed $\varepsilon_{t} \sim \mathrm{N}\left(0, \sigma^{2}\right)$.

sion slope after the shift and $e_{t}$ are the white noise errors. To verify whether the relationships are similar before and after the shift, we test whether the slopes are equal $\left(b_{1}=b_{2}\right)$ using the Student test statistic (with $n-4$ degrees of freedom) described by Paternoster et al. (1998):

$t=\frac{b_{1}-b_{2}}{s_{b_{1}-b_{2}}}$

$s_{b_{1}-b_{2}}=\sqrt{s_{b_{1}}^{2}+s_{b_{2}}^{2}}$,

where $b_{1}$ and $b_{2}$ are estimated using least squares with $s_{b_{1}}$ and $s_{b_{2}}$ being the respective standard errors.

\section{Results}

Figure 2 presents the results of the change-point analysis on gridded SST observations for the North Pacific. This reveals a predominant shift in 1977 over the Gulf of Alaska region, which also extends as a coastal band towards the California Current region and the Bering Sea. A late 1980s shift is detected in a smaller area in the middle of the gyre. It must be noted that spatial homogeneity of the shift is to be expected here given that the ERSST dataset is produced using empirical orthogonal functions (Smith and Reynolds, 2003).

In the observed SST time series averaged over the Gulf of Alaska, a statistically significant shift is detected and manifests as a rapid increase in the mean of $\sim 1{ }^{\circ} \mathrm{C}$ after a decreasing trend (Fig. 3a). In the model physical time series (which are identical in all five OBGC models), SST exhibits the same signal as the observations: a shift in the intercept 


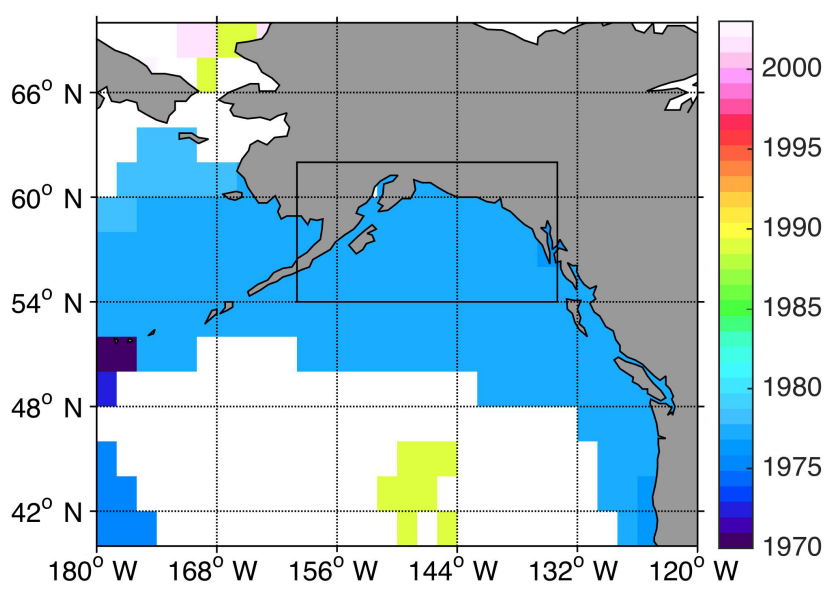

Figure 2. Timing of shift detected in observed sea surface temperature in the North Pacific using change-point analysis showing a predominant signal in 1977. White areas indicate where a shift is not significant ( $p$ value $>0.05$ ). The black box indicates the Gulf of Alaska region used in this study.

and gradient occurring in 1976, while the MLD is best represented by a linear trend. However, the model MLD time series show strong decadal variability with large changes occurring in the mid-1970s and at the beginning of the 1990s (Fig. 3b-c). Results of change-point analysis on large-scale oscillations characterizing the climate over the region are also presented in Fig. 3d-f and show a significant shift in the PDO in the late 1970s while the NPGO and MEI annual time series do not indicate a shift.

The change-point analysis was performed on $\mathrm{PC} 1$ for each model (Fig. 4, Table 3), which explains most of the variance for each model (except MEDUSA, $36 \%$ of variance explained; Table 4). HadOCC exhibits a shift in 1977 in PC1 (Table 3), for which all variables except MLD have large relative contributions ( $>10 \%$ relative contribution, Table 4$)$. The first principal component in Diat-HadOCC exhibits a shift in 1976 and explains $63 \%$ of the total variance. The variable offering the smallest relative contribution is again the MLD (Table 4). In MEDUSA, a shift is also detected in the late 1970s in the first component, which explains only $36 \%$ of the variance. The SST, CHL and nutrients are the most important variables with relative contributions larger than $10 \%$ (Table 4). The MLD has a relative contribution of $0.94 \%$ to PC1 (Table 4). The relative contributions of the nutrients in the HadOCC, Diat-HadOCC and MEDUSA late 1970s shift detected in the first principal component suggests the controlling factor is nutrient limitation (i.e. bottom-up control) in these models. In ERSEM and PlankTOM10, there are no shifts detected in the first principal component. Similar results are obtained when excluding SST and MLD from PC1 (Appendix A).

The results of the change-point analysis on all observational and model individual time series are presented in Ap-
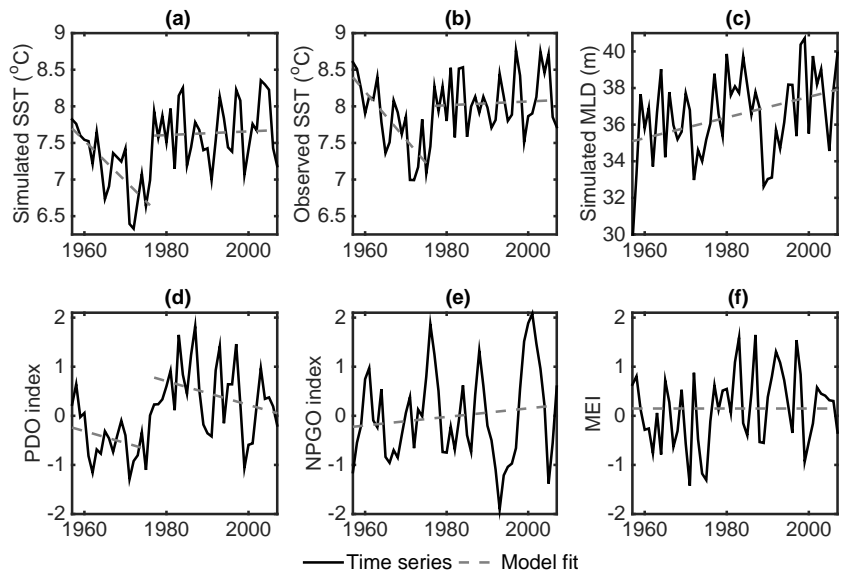

Figure 3. Time series of (a) simulated sea surface temperature (SST), (b) observed SST and (c) simulated mixed-layer depth (MLD) for the Gulf of Alaska. The simulated time series of SST and MLD are the same in the five ocean models used. Time series of large-scale oscillations representing the climate in the Gulf of Alaska: (d) Pacific Decadal Oscillation (PDO) index, (e) North Pacific Gyre Oscillation (NPGO) index and (f) multivariate El Niño Southern Oscillation index (MEI). The grey dotted lines represent the statistical model chosen (see Table A1) to fit these time series. Both the simulated SST and observed SST exhibit a significant shift in intercept and trend occurring in 1976 ( $p$ value $<0.05$, see Table A1). The MLD time series do not exhibit a significant shift and is best represented by a linear trend. Among the large-scale oscillations, only the PDO exhibits a significant shift in 1976.
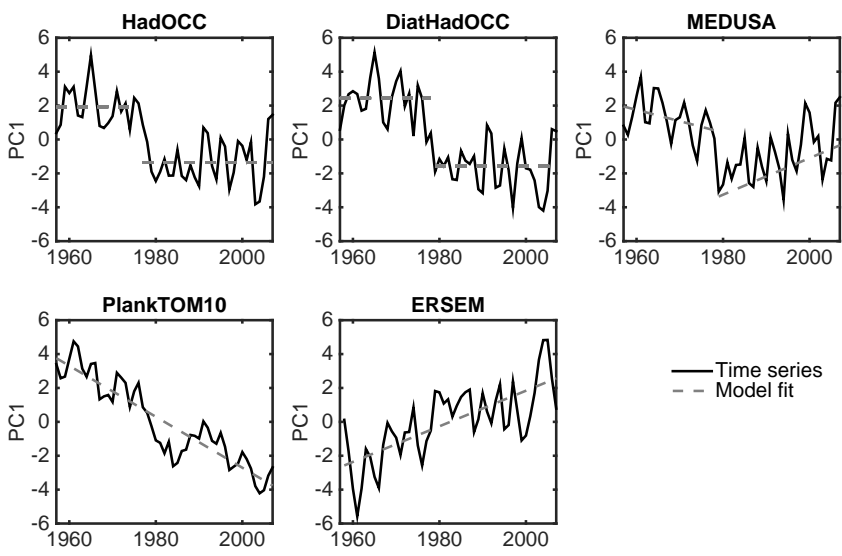

Figure 4. First principal component (PC1) of sea surface temperature, mixed-layer depth, surface dissolved inorganic nitrogen, silica, iron, surface chlorophyll, integrated primary production, total surface phytoplankton and zooplankton biomass (if available) averaged over the Gulf of Alaska for each model. The grey dotted lines represent the statistical model chosen to fit these time series (see Table 3). HadOCC, DiatHadOCC and MEDUSA PC1 exhibit a significant shift in the late 1970s.

pendix B (Table B1). The fit of the most appropriate statistical models for the biological variables for each OBGC model are also presented in Appendix B (Figs. B1-B5). Statistically 
Table 3. Results from change-point detection analysis on the first principal component (PC1) of each model. Years in bold have a significant shift ( $p$ value $<0.05)$.

\begin{tabular}{lllrrr}
\hline Model & $\begin{array}{l}\text { Shift } \\
\text { year }\end{array}$ & Shift type & $\begin{array}{r}\text { SIC } \\
\text { (Null model) }\end{array}$ & SIC & $p$ value \\
\hline HadOCC & $\mathbf{1 9 7 7}$ & mean & 180.62 & 225.69 & $<0.01^{\mathrm{a}, \mathrm{c}}$ \\
DiatHadOCC & $\mathbf{1 9 7 6}$ & mean & 185.55 & 240.42 & $<0.01^{\mathrm{c}}$ \\
MEDUSA & $\mathbf{1 9 7 8}$ & trend and intercept & 184.54 & 207.00 & $<0.01^{\mathrm{c}}$ \\
PlankTOM10 & 1987 & intercept & 141.14 & 152.90 & $0.21^{\mathrm{c}}$ \\
ERSEM & 1987 & intercept & 189.09 & 192.55 & $0.63^{\mathrm{c}}$ \\
\hline
\end{tabular}

${ }^{a}$ Residuals not normally distributed (Lilliefors test, $5 \%$ critical level). ${ }^{\mathrm{b}}$ Residual variance not constant (Fisher test, $5 \%$ critical level). ${ }^{\mathrm{c}}$ Residuals not independent (Durbin-Watson test, $5 \%$ critical level): the Monte Carlo simulations to estimate the $p$ value incorporates the first-order autocorrelation of the residuals.

Table 4. Results of the principal component analysis: percentage of variance explained by the first principal component (PC1) and relative contributions of the different variables to this component.

\begin{tabular}{lrrrrrrrrrr}
\hline \multirow{2}{*}{ Model } & \multicolumn{1}{c}{\begin{tabular}{c} 
Variance \\
\cline { 3 - 10 }
\end{tabular}} & \multicolumn{10}{c}{ Relative contribution (\%) } \\
\cline { 3 - 11 } & explained (\%) & SST & MLD & CHL & PP & PHY & ZOO & DIN & FE & SI \\
\hline HadOCC & 61.09 & 13.53 & 2.69 & 19.02 & 11.08 & 18.91 & 16.82 & 17.94 & - & - \\
DiatHadOCC & 63.42 & 10.41 & 1.92 & 13.88 & 12.84 & 13.93 & 13.51 & 11.85 & 12.50 & 9.16 \\
MEDUSA & 36.33 & 10.16 & 0.94 & 15.91 & 7.34 & 9.90 & 6.18 & 19.07 & 16.31 & 14.18 \\
PlankTOM10 & 66.05 & 7.74 & 6.25 & 14.29 & 13.99 & 14.59 & 14.27 & 14.30 & 1.10 & 13.48 \\
ERSEM & 50.74 & 8.88 & 1.31 & 14.08 & 15.05 & 8.32 & 12.71 & 9.63 & 15.86 & 14.18 \\
\hline
\end{tabular}

significant shifts are found more often in the simpler OBGC models (HadOCC, Diat-HadOCC and MEDUSA) than the complex ones (Table B1), which is consistent with the results obtained on the first principal component for each model. Of the statistically significant shifts identified in these models, the majority occurred in the late 1970s. In HadOCC, the late 1970s shift corresponds to a decrease in DIN, CHL, PHY and ZOO, while a large increase in PP is detected in 1991. Nevertheless, PP is decreasing over the period 1957-1990 (Fig. B1). In Diat-HadOCC, all parameters exhibit a shift in the late 1970s, although it is not significant in PHY and ZOO. The significant shifts in the late 1970s manifest as a decrease in SI, FE, CHL and PP. In MEDUSA, shifts in DIN and FE (although not significant) are identified in the late 1970s. ERSEM exhibits a significant shift in CHL in the late 1970s, while PlankTOM10 does not have any significant shifts for that period.

As a visual support for the change-point analysis, cumulative sums of the $z$ scores of each time series within each model are presented in Fig. 5. A shift in a time series is revealed by a change of slope of the cumulative sums. The change of slope in SST is sharp, as one would expect given the significant shift detected. Even though our analysis suggests a long-term deepening of the MLD rather than an abrupt change, subtle decreases are suggested by smooth change of slope in the cumulative sum in the late 1970s and 1980s. These changes are clearly propagated to the other parameters in HadOCC, DiatHadOCC and MEDUSA with a sharp change of slope, but smoother change in ERSEM and PlankTOM10.

We further investigate the forcing-response relationship between SST and the biological variables (CHL, PP, PHY, ZOO) in HadOCC, DiatHadOCC and MEDUSA (Fig. 6) before and after 1977, as a significant shift is present in PC1 in these models. The slopes of the linear relationships between SST and the biological variables are mostly similar before and after 1977 (Table 5). This is consistent with a linear, rather than nonlinear, response to changes in SST forcing. There is one exception for ZOO for which the difference in slopes is significant with a stronger relationship after 1977 in HadOCC and DiatHadOCC (Table 5, Fig. 6), which could suggest an amplified nonlinear response.

\section{Discussion and conclusions}

Using the Gulf of Alaska as a case study, our results demonstrate the usefulness of OBGC models to infer the chain of events responsible for regime shifts, especially in regions where observations are scarce. Although there are many definitions of regime shifts in the literature, they can be generally described as an abrupt change (e.g. from one year to the next) that occurs across both physical and biological parts of the ecosystem. Therefore, to determine if a regime shift has occurred in the five OBGC models tested here the shift has to be traceable from physical parameters through to biological parameters. With the change-point detection method used 
Table 5. Forcing-response regressions in HadOCC, Diat-HadOCC and MEDUSA with sea surface temperature (SST) as the physical forcing and surface chlorophyll (CHL), integrated primary production (PP), total surface phytoplankton (PHY) and zooplankton biomass (ZOO) as the responses. The slopes of the linear regressions between the forcing and response before and after the shift are compared using a test of equality of two regression slopes. Bold indicates significant slope differences ( $p$ value $<0.05)$.

\begin{tabular}{|c|c|c|c|c|c|}
\hline \multicolumn{6}{|c|}{ HadOCC } \\
\hline Forcing & Response & $\begin{array}{r}\text { Slope 1957-1976 } \\
\text { (standard error) }\end{array}$ & $\begin{array}{r}\text { Slope 1977-2007 } \\
\text { (standard error) }\end{array}$ & Test statistic & $p$ value \\
\hline \multirow[t]{4}{*}{$\mathrm{SST}$} & $\mathrm{CHL}$ & $-0.025(0.028)$ & $-0.008(0.024)$ & 1.407 & 0.166 \\
\hline & $\mathrm{PP}$ & $0.000(0.005)$ & $0.021(0.011)$ & -1.703 & 0.095 \\
\hline & PHY & $-0.008(0.014)$ & $-0.030(0.013)$ & 1.179 & 0.245 \\
\hline & $\mathrm{ZOO}$ & $0.002(0.004)$ & $-0.012(0.003)$ & 2.823 & 0.007 \\
\hline \multicolumn{6}{|c|}{ Diat-HadOCC } \\
\hline Forcing & Response & $\begin{array}{r}\text { Slope } 1957-1976 \\
\text { (standard error) }\end{array}$ & $\begin{array}{r}\text { Slope 1977-2007 } \\
\text { (standard error) }\end{array}$ & Test statistic & $p$ value \\
\hline \multirow[t]{4}{*}{$\mathrm{SST}$} & $\mathrm{CHL}$ & $-0.121(0.071)$ & $-0.217(0.052)$ & 1.095 & 0.279 \\
\hline & $\mathrm{PP}$ & $-0.033(0.012)^{\mathrm{b}}$ & $-0.022(0.012)$ & -0.666 & 0.508 \\
\hline & PHY & $-0.028(0.025)$ & $-0.069(0.018)$ & 1.345 & 0.185 \\
\hline & $\mathrm{ZOO}$ & $-0.002(0.006)$ & $-0.018(0.005)$ & 2.034 & 0.048 \\
\hline \multicolumn{6}{|c|}{ MEDUSA } \\
\hline Forcing & Response & $\begin{array}{r}\text { Slope 1957-1976 } \\
\text { (standard error) }\end{array}$ & $\begin{array}{r}\text { Slope 1977-2007 } \\
\text { (standard error) }\end{array}$ & Test statistic & $p$ value \\
\hline \multirow[t]{4}{*}{ SST } & $\mathrm{CHL}$ & $0.002(0.006)$ & $-0.013(0.007)$ & 1.476 & 0.146 \\
\hline & $\mathrm{PP}$ & $0.019(0.004)$ & $0.020(0.005)$ & -0.129 & 0.898 \\
\hline & PHY & $0.014(0.004)$ & $0.006(0.004)$ & 1.458 & 0.151 \\
\hline & $\mathrm{ZOO}$ & $0.039(0.007)$ & $0.027(0.007)^{\mathrm{b}}$ & 1.132 & 0.263 \\
\hline
\end{tabular}

${ }^{\mathrm{a}}$ Residuals not normally distributed (Lilliefors test, $5 \%$ critical level). ${ }^{\mathrm{b}}$ Residual variance not constant (Breusch Pagan test, $5 \%$ critical level)

here, we found statistically significant shifts in the late 1970s in the Gulf of Alaska simulated in five OBGC models. A shift in model SST occurred in 1976 and matched a shift in observed SST. This abrupt change in SST was followed by an overall decrease in nutrients and productivity. The three OBGC models simulating an abrupt change in 1977 in PC1 (i.e. HadOCC, DiatHadOCC and MEDUSA) are consistent in the direction of change (Fig. 4). The decrease in nutrients after 1977 seems to be the dominant driver in the reduction in productivity and outweighs changes due to fluctuations in light availability. The dominance of declining nutrients in explaining the variability in the principal components of HadOCC, Diat-HadOCC and MEDUSA, supports this hypothesis.

Previous studies have linked the late 1970s shift in the North Pacific with the PDO, which switched from a negative to a positive state in 1976/77 (Mantua et al., 1997). The PDO fluctuations have been suggested to exhibit a red noise response to atmospheric noise and ENSO events (Newman et al., 2003), thereby raising the possibility of a link between ENSO and the North Pacific shift in the late 1970s. Nevertheless, the PDO (and implicitly ENSO) alone is not enough to characterize the North Pacific climate (Bond et al., 2003). Alternatively, the North Pacific Gyre Oscillation (NPGO) has been suggested as a global-scale mode of variability that plays an important role in decadal changes in marine ecosystems (DiLorenzo et al., 2008). For example, in the California Current, the PDO correlates with SST while NPGO is more closely related to variability in salinity, nutrient and primary production (DiLorenzo et al., 2008). Thus, if both the PDO and NPGO fluctuations drive changes in the North Pacific climate and ecosystem functioning, the question arises whether either or both of these indices exhibit a shift at a similar time. Underscoring some of the conclusions of the prior work discussed above, the shift in 1976/77 manifests in the PDO index, but notably we find no significant shifts in the multivariate ENSO index or the NPGO index. Clearly, by detecting a shift in the late 1970s in PDO only we cannot conclusively tie the PDO and untie the NPGO and ENSO to the shift in climate and ecosystem dynamics of the Gulf of Alaska. However, these corresponding changes are an important piece of information to future work aimed at determining causal mechanisms, mode of teleconnection and 

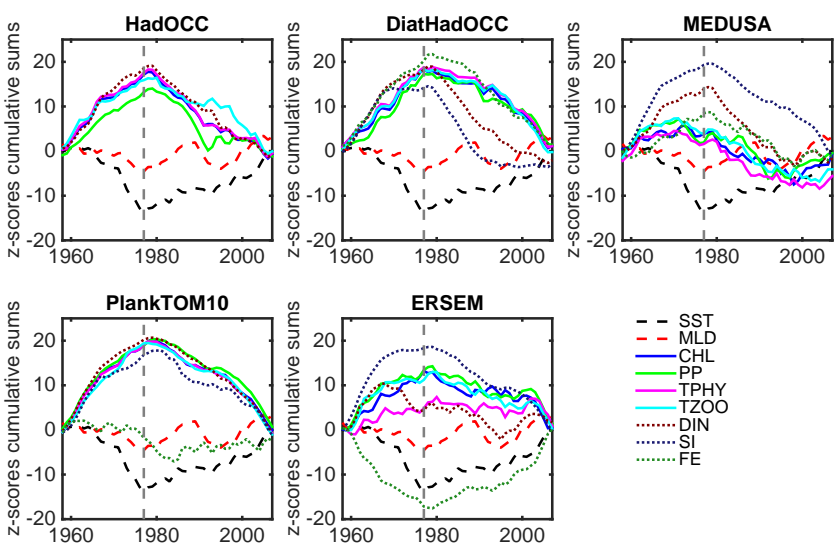

Figure 5. Cumulative sums of the $z$ scores of simulated sea surface temperature (SST), mixed-layer depth (MLD), surface dissolved inorganic nitrogen (DIN), silica (SI), iron (FE), surface chlorophyll (CHL), integrated primary production (PP), total surface phytoplankton (PHY) and zooplankton (ZOO) biomass for each model averaged over the Gulf of Alaska region. $Z$ scores are calculated by subtracting the mean and dividing by the standard deviation of each time series. Cumulative sums of the $z$ scores are then calculated. The vertical lines in 1977 provide a guide to the eye showing where the slopes change after 1977.

coupled physical/biogeochemical dynamics that link global climate patterns to ocean fertility of the Gulf of Alaska.

In conclusion, the 1977 regime shift in the Gulf of Alaska was observed in sea surface temperature and in the abundance of a range of commercial fish species (McGowan et al., 1998). Here, we infer the behaviour of the nutrients and lower trophic levels using OBGC models, and the relationship of these changes to physical variables that are plausible drivers. Our novel approach based on change-point detection offers a helpful framework to evaluate previous modelling studies that have attempted to reproduce the extent of changes from physics to biology for the late 1970s shift in the Gulf of Alaska (e.g. Polovina et al., 1995; Haigh et al., 2001; Capotondi et al., 2005; Alexander et al., 2008). For example, Haigh et al. (2001) used the Miami isopycnic coordinate ocean model combined with an ecosystem model of four compartments (Denman and Peña, 1999) to show that a year-round deepening of the mixed-layer depth after 1976 led to a slight decrease in nutrients and phytoplankton as well as zooplankton biomass. These findings are broadly consistent with the model simulations analysed here. Other studies instead suggest that the MLD shoaled after 1977 resulting in increased plankton production in the region. This is the case in the Polovina et al. (1995) study, which suggested that shoaling in the spring/winter MLD led to increased productivity in a plankton population dynamics model. More recently, Alexander et al. (2008) used the National Center for Atmospheric Research Climate System Model Ocean Model (NCOM) combined with a biological model that contains 10 compartments (Chai et al., 2002) to simulate the chain of
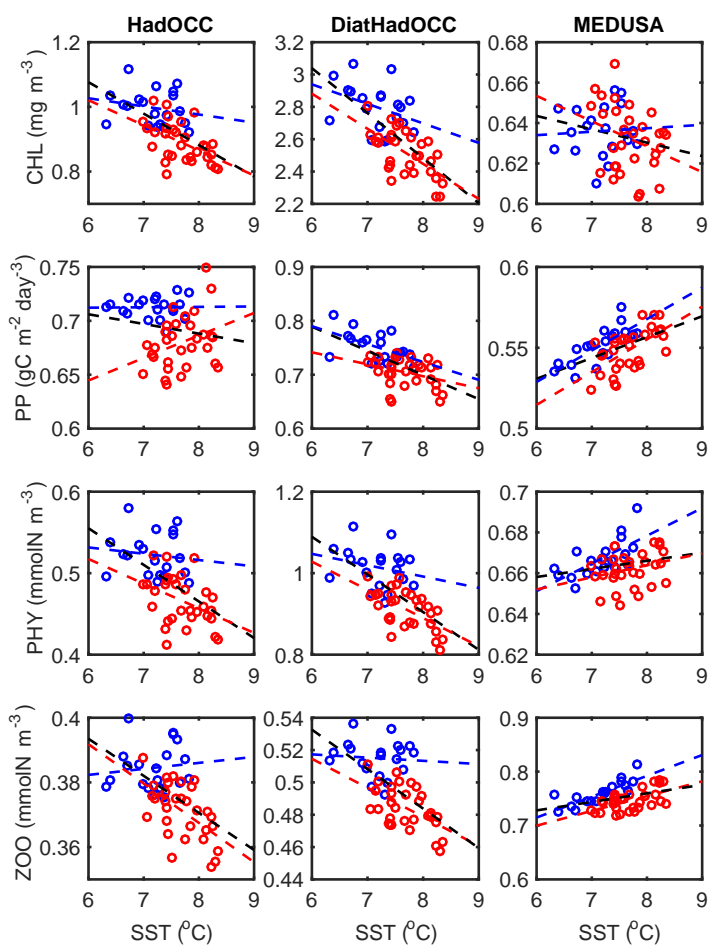

- 1957-1976 ○ 1977-2007- - Fit 1957-1976- - Fit 1977-2007- - Fit 1957-2007

Figure 6. Relationships matrix between simulated sea surface temperature (SST) and the biological variables over the Gulf of Alaska region. Columns represent different models (HadOCC, DiatHadOCC and MEDUSA) and rows represent different biological variables (surface chlorophyll (CHL), integrated primary production (PP), total surface phytoplankton (PHY) and zooplankton biomass (ZOO)). Linear relationships are inferred for the periods 1957-1976, 1977-2007 and 1957-2007 using least square regression. Table 5 presents test results on the similarity of these relationships.

events in the region. In that study, an increase in SST simulated in the late 1970s is accompanied by a shoaling in the winter mixed-layer depth, giving rise to an early spring increase in primary production, phytoplankton and zooplankton biomass followed by a late spring decline in both phytoplankton and zooplankton biomass. Despite the caveat that we are analysing annual mean time series it is important to point out the contradictory direction of change in mixedlayer depth. Possibly reconciling this discrepancy, Capotondi et al. (2005) suggest, based on NCOM model simulations, a deepening trend in MLD in a broad band along the coast and shoaling in the central part of the Gulf of Alaska. Thus, the comparison of the various attempts to simulate the late 1970s regime shift of the Gulf of Alaska raises the possibility that the observed abrupt and spatially coherent ecosystem change was actually caused by a previously unappreciated heterogeneous set of environmental changes with distinct spatial pattern and timing in the annual cycle. If so, the inherent assumption underpinning our own and previous 
work to understand the Gulf of Alaska ecosystem shift as a single mechanistic causal sequence may be overly simplistic. Consequently, future analysis aimed at spatial and temporal heterogeneity of abrupt regional ecosystem change has the potential to greatly improve our understanding of the underlying dynamics and the vulnerability of marine ecosystems to abrupt future changes.

A second major outcome of this study involves the role of model complexity in determining a system's propensity for abrupt ecosystem change. All the OBGC models used in this study have the same underlying physical model, and were run with the same initial conditions and forcing fields. Their performance in terms of a fit to observations has been assessed globally in a previous study by Kwiatkowski et al. (2014), showing that all models have skills in simulating some variables, but simpler models were broadly closer to observations overall. In the Gulf of Alaska, the five models systematically differ in nutrient and biological responses as a function of model ecosystem complexity. Simple to intermediate complexity models such as HadOCC, Diat-HadOCC, and MEDUSA simulate a shift in the late 1970s, which manifests as an abrupt change in SST and many nutrients and biological parameters. As the model complexity increases to PlankTOM10 and ERSEM, these changes are mostly in the same direction but become less abrupt. The simpler models have fewer plankton groups responding to environmental changes (both HadOCC and Diat-HadOCC have one zooplankton group, and Diat-HadOCC has two phytoplankton groups), which might explain a more direct response than a model with a larger number of plankton groups interacting with each other. More complex models could potentially unveil shifts in the community structure (i.e. increase of a certain type of plankton and decrease of another one), as regime shifts can affect different species in opposite ways (Benson and Trites, 2002). Feedbacks and interactions between groups in the models are in need of thorough exploration to determine how they affect the simulation of observed regime shifts. Such differences between model results raise the question as to what degree of model complexity is needed to appropriately simulate the complexity of regime shifts in the real world. Extremely simple models are easy to interpret but may not be able to reproduce realistic behaviour, while too much complexity will lead to uncertainty and problems in interpretation of the model (Allen et al., 2010). Given the observed differences between models, our results suggest caution on relying on a single "ultimate" model for understanding regime shifts behaviour and rather favour multiple lower to intermediate complexity models, as recommended by Fulton et al. (2003). However, our results should not be generalized too easily, as we focused uniquely on the Gulf of Alaska region here. More complex models could outperform simple models in different ecosystems. For example, higher complexity models have been suggested to be more portable (i.e. ability to perform well in diverse regions and physical settings) in a comparative study focusing on the equatorial
Pacific and Arabian Sea (Friedrichs et al., 2007). Future work should involve a regime shift analysis in several ecosystems using models with traceable complexity. Furthermore, an ensemble approach to quantify the effects of model and internal variability uncertainty in regime shift detection would be beneficial.

Our analysis suggests that the Gulf of Alaska regime shift is consistent with a linear response to physical forcings on lower trophic levels, showing a bottom-up response due to changes in the physical environment controlled via nutrient limitation, with a potential amplified response from $\mathrm{ZOO}$ (only in HadOCC and Diat-HadOCC). This result is in agreement with the linear tracking window hypothesis (Hsieh and Ohman, 2006), which suggests that some populations can respond linearly to abrupt changes in physical forcing, as opposed to an amplified nonlinear response to small changes in forcing (e.g. Scheffer et al., 2009). However, it must be noted that our analysis is lacking top-down controls from upper trophic levels beyond zooplankton, and thus only partly resolves possible explanations for the observed regime shifts in the Gulf of Alaska. Many drivers (and their synergistic effects) may combine to fully explain regime shifts (Lindegren et al., 2012; Litzow et al., 2014). Models including upper trophic levels able to simulate regime shifts would also be beneficial to better understand the mechanisms leading to the shift and estimate critical thresholds.

Finally, beyond model complexity and the spatial and temporal resolution at which the output is analysed, the stateof-the-art in statistical techniques for regime shift detection is an active area of research. Here we employ an approach to detect shifts and distinguish them from a long-term trend and background red noise, i.e. evaluate if the shift is unusually large given the fluctuations that would be expected in the presence of autocorrelation and/or a trend (Beaulieu et al., 2012), which is an improvement over previous methodologies. A main current limitation of this methodology is the ability to detect at most one shift and in one time series at a time (univariate), but work to extend the methodology to detect multiple shifts in a multivariate setting is under way. Furthermore, we distinguish against a background of red noise, which is assumed constant through the time series, but the presence of changes in the red noise through time could affect the results. For example, a recent study suggests a "reddening" of the PDO and North Pacific SST as an explanation for occurrences of abrupt changes in the North Pacific ecosystem (Boulton and Lenton, 2015). However, this is unlikely to affect our results given the timescale (annual means) and length of the time series (51 years) used in this study. Further, we suggest here that analysis of the forcing-response relationship helps to distinguish between a regime shift with a linear response to a shift in forcing, and a nonlinear response after crossing a forcing threshold, as originally proposed by Bestelmeyer et al. (2011). Here we used a test that is based on a quantitative comparison of the forcing-response relationship before and after the shift. This 
approach can be used to detect other marine or terrestrial regime shifts and distinguish between a linear and a nonlinear response to external forcing. For management purposes, distinguishing between these two types of forcing-response relationship producing regime shifts is critical, as they will lead to different management and policy incentives (Kelly et al., 2015). For example, a routine monitoring of thresholdbased systems leads to better management outcomes than "threshold-blind" management, i.e. when ignoring the possibility of a threshold and assuming a linear forcing-response relationship (Kelly et al., 2015).

\section{Data availability}

The outputs from five ocean biogeochemical models averaged over the Gulf of Alaska are available as a Supplement to this article. Observed sea surface temperature data were extracted from the Extended Reconstructed Sea Surface Temperature (ERSST) dataset (version 3b; Smith and Reynolds, 2003; Smith et al., 2008) downloaded from https://www. ncdc.noaa.gov/ersst/. The Pacific Decadal Oscillation index (Mantua et al., 1997) was downloaded from http://www. atmos.washington.edu/ mantua/abst.PDO.html. The Multivariate El Niño Southern Oscillation Index (Wolter and Timlin, 1998) was downloaded from http://www.esrl.noaa.gov/ $\mathrm{psd} / \mathrm{enso} / \mathrm{mei} /$ and the North Pacific Gyre Oscillation index (DiLorenzo et al., 2008) was downloaded from http://www. o3d.org/npgo/npgo.php. 


\section{Appendix A}

This appendix presents the results of the principal component analysis and change-point analysis on PC1 of each model excluding the physical parameters (SST and MLD).

Table A1. Results from change-point detection analysis on the first principal component (PC1) of each model. Years in bold have a significant shift $(p$ value $<0.05)$.

\begin{tabular}{lllrrr}
\hline Model & $\begin{array}{l}\text { Shift } \\
\text { year }\end{array}$ & Shift type & $\begin{array}{r}\text { SIC } \\
\text { (Null model) }\end{array}$ & SIC & $p$ value \\
\hline HadOCC & $\mathbf{1 9 7 7}$ & mean & 176.15 & 220.43 & $<0.01^{\mathrm{a}, \mathrm{c}}$ \\
DiatHadOCC & $\mathbf{1 9 7 6}$ & mean & 181.69 & 236.08 & $<0.01^{\mathrm{c}}$ \\
MEDUSA & $\mathbf{1 9 7 8}$ & trend and intercept & 175.85 & 205.84 & $<0.01$ \\
PlankTOM10 & 1987 & intercept & 133.19 & 144.83 & $0.19^{\mathrm{c}}$ \\
ERSEM & 1987 & intercept & 188.46 & 192.14 & $0.64^{\mathrm{c}}$ \\
\hline
\end{tabular}

a Residuals not normally distributed (Lilliefors test, $5 \%$ critical level). ${ }^{\mathrm{b}}$ Residual variance not constant (Fisher test, $5 \%$ critical level). ${ }^{\mathrm{c}}$ Residuals not independent (Durbin-Watson test, $5 \%$ critical level): the Monte Carlo simulations to estimate the $p$ value incorporates the first-order autocorrelation of the residuals.

Table A2. Results of the principal component analysis: percentage of variance explained by the first principal component (PC1) and relative contributions of the different variables to this component.

\begin{tabular}{lrrrrrrrr}
\hline \multirow{2}{*}{ Model } & Variance & \multicolumn{7}{c}{ Relative contribution (\%) } \\
\cline { 3 - 9 } & explained (\%) & CHL & PP & PHY & ZOO & DIN & FE & SI \\
\hline HadOCC & 77.13 & 22.62 & 13.93 & 22.70 & 19.67 & 21.09 & - & - \\
DiatHadOCC & 74.90 & 15.60 & 14.52 & 15.74 & 15.23 & 13.68 & 14.50 & 10.74 \\
MEDUSA & 45.29 & 15.34 & 13.30 & 15.38 & 12.68 & 17.26 & 12.34 & 13.70 \\
PlankTOM10 & 79.37 & 16.52 & 16.44 & 16.85 & 16.16 & 16.67 & 1.71 & 15.64 \\
ERSEM & 61.99 & 14.77 & 16.84 & 9.21 & 14.30 & 11.95 & 17.01 & 15.91 \\
\hline
\end{tabular}




\section{Appendix B:}

This appendix presents the results of the change-point analysis for all parameters simulated from the five models. The physical parameters (SST and MLD) are omitted here as they are presented in Fig. 3. The chosen model for each variable and each OBGC model is presented in Table B1.
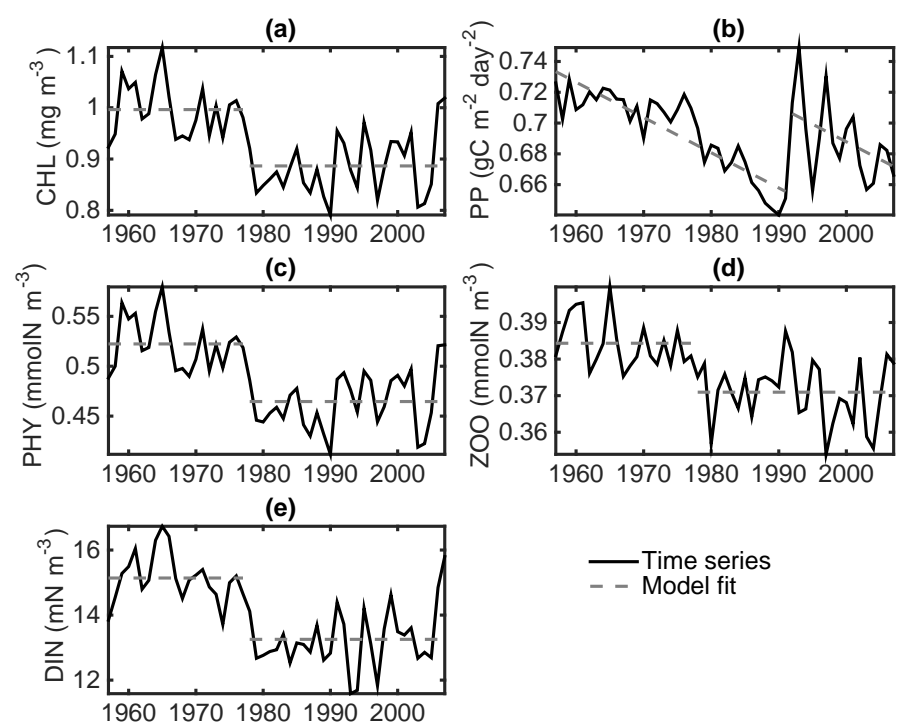

$$
\begin{aligned}
& \text { - Time series } \\
& - \text { Model fit }
\end{aligned}
$$

19601970198019902000

Figure B1. Time series of (a) surface chlorophyll, (b) integrated primary production, (c) total surface phytoplankton, (d) zooplankton biomass and (e) surface dissolved inorganic nitrogen simulated with the HadOCC model and averaged over the Gulf of Alaska region. The dotted lines represent the statistical model selected. 

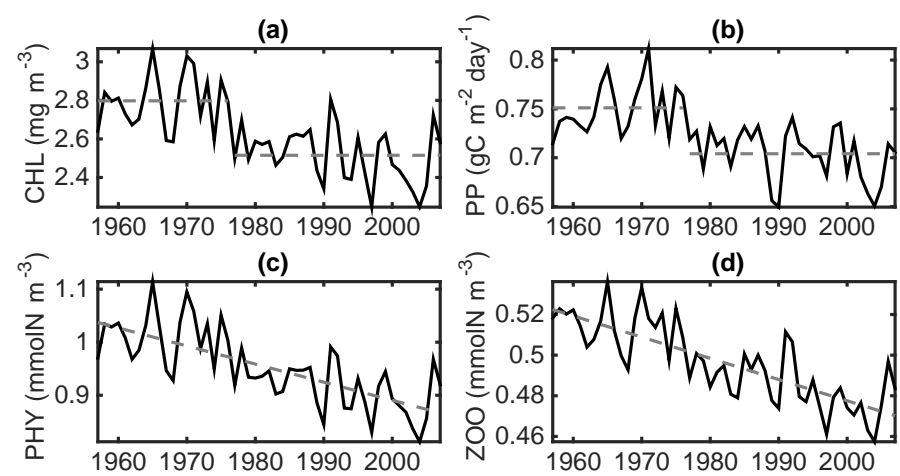

(e)

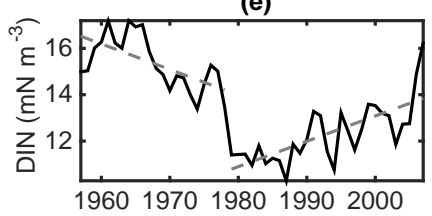

(f)
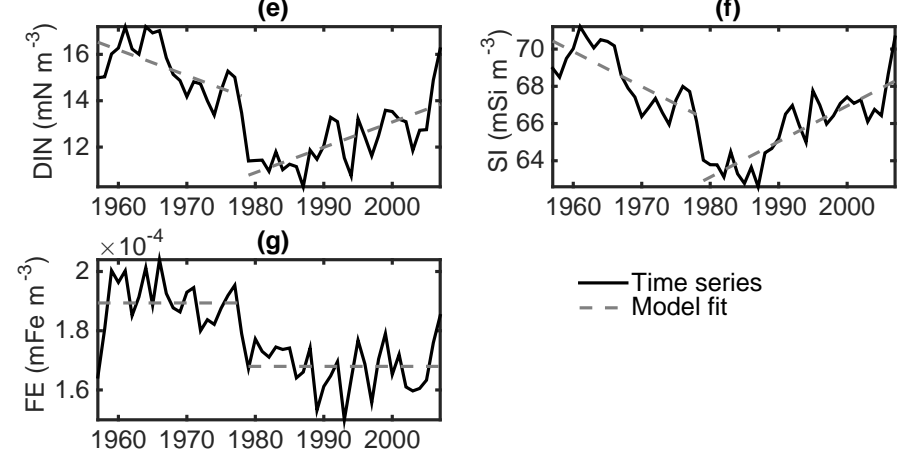

— Time series

- - Model fit

Figure B2. Time series of (a) surface chlorophyll, (b) integrated primary production, (c) total surface phytoplankton, (d) zooplankton biomass and (e) surface dissolved inorganic nitrogen, (f) silica and (g) iron simulated with the DiatHadOCC model and averaged over the Gulf of Alaska region. The dotted lines represent the statistical model selected.
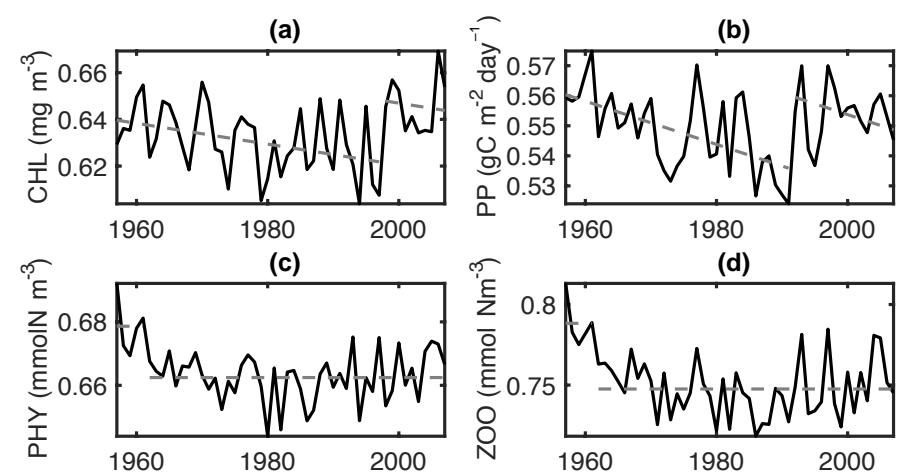

(e)
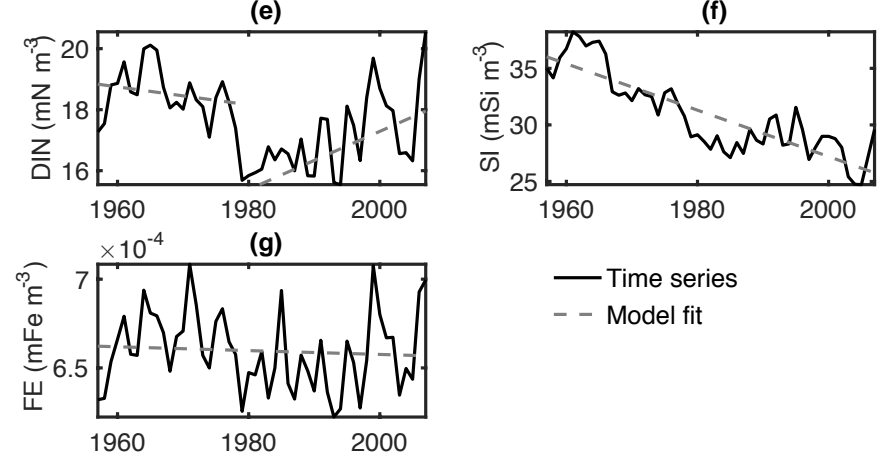

$$
\begin{aligned}
& \text { - Time series } \\
& -- \text { Model fit }
\end{aligned}
$$

Figure B3. Time series of (a) surface chlorophyll, (b) integrated primary production, (c) total surface phytoplankton, (d) zooplankton biomass and (e) surface dissolved inorganic nitrogen, (f) silica and (g) iron simulated with the MEDUSA model and averaged over the Gulf of Alaska region. The dotted lines represent the statistical model selected. 

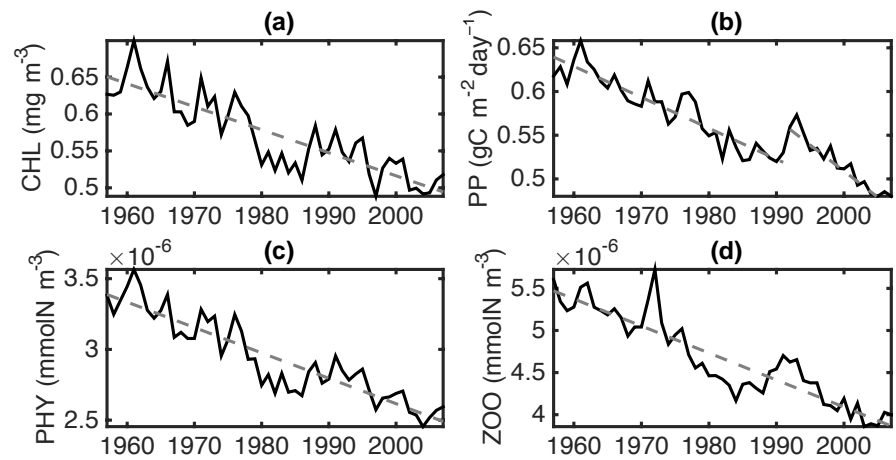

(e)

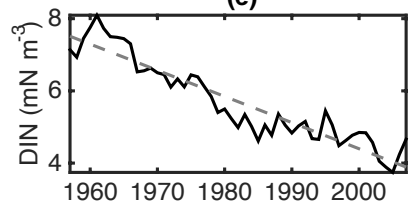

(f)
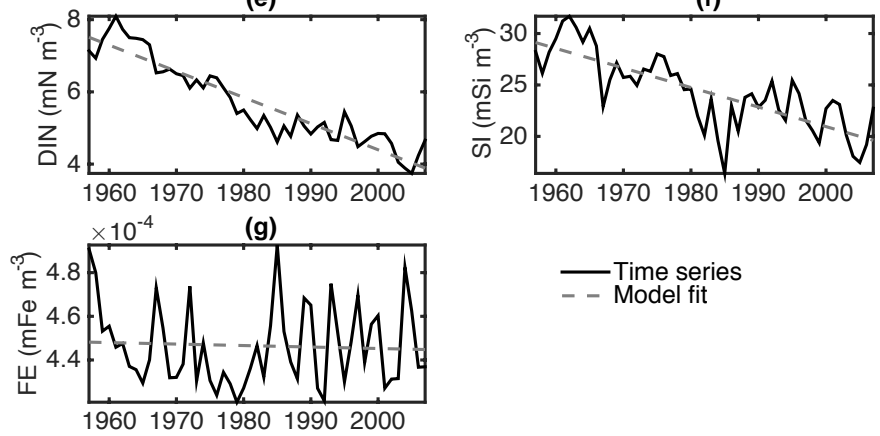

- Time series

- - Model fit

Figure B4. Time series of (a) surface chlorophyll, (b) integrated primary production, (c) total surface phytoplankton, (d) zooplankton biomass and (e) surface dissolved inorganic nitrogen, (f) silica and (g) iron simulated with the PlankTOM10 model and averaged over the Gulf of Alaska region. The dotted lines represent the statistical model selected.
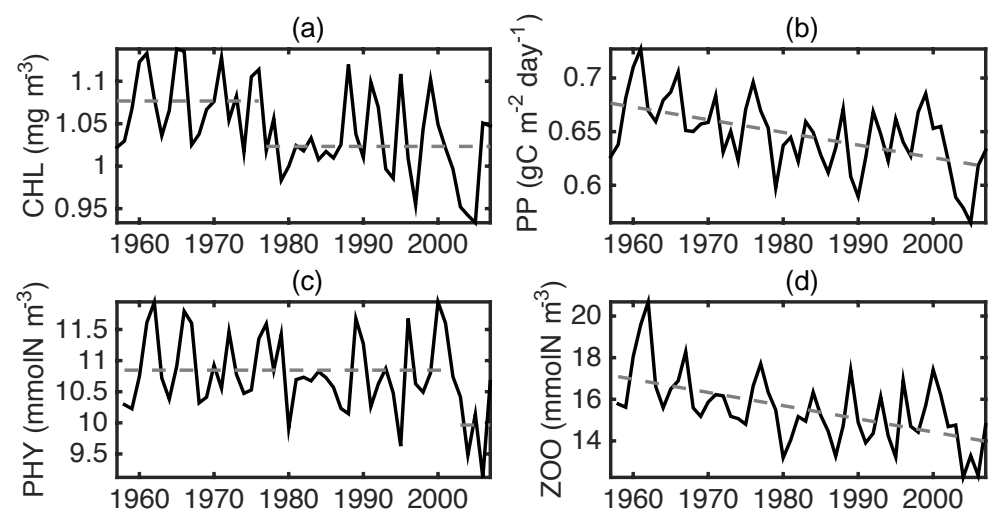

(d)
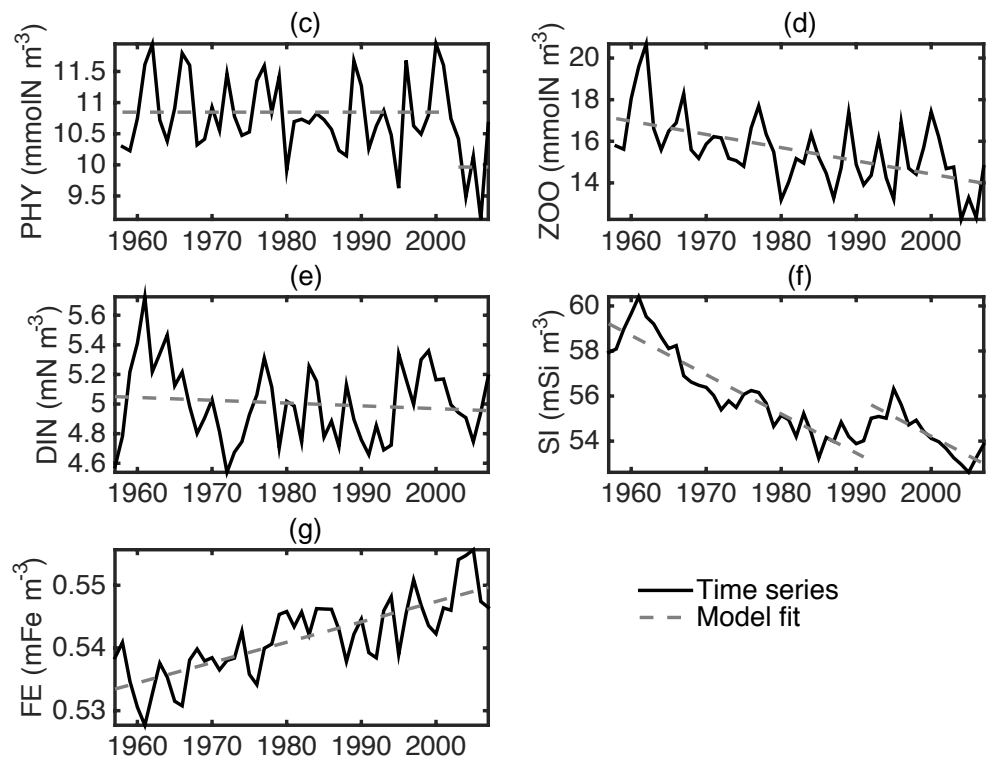

- Time series

- Model fit

Figure B5. Time series of (a) surface chlorophyll, (b) integrated primary production, (c) total surface phytoplankton, (d) zooplankton biomass and (e) surface dissolved inorganic nitrogen, (f) silica and (g) iron simulated with the ERSEM model and averaged over the Gulf of Alaska region. The dotted lines represent the statistical model selected. 
Table B1. Results from change-point detection analysis for all observational and modelled time series. Years in bold have a significant shift $(p$ value $<0.05)$

\begin{tabular}{|c|c|c|c|c|c|c|}
\hline & Parameter & $\begin{array}{l}\text { Shift } \\
\text { year }\end{array}$ & Shift type & $\begin{array}{r}\text { SIC } \\
(\text { Null model })\end{array}$ & SIC & $p$ value \\
\hline \multirow[t]{4}{*}{ Observations } & SST & 1976 & trend and intercept & 52.79 & 70.63 & $<0.01$ \\
\hline & PDO & 1976 & intercept & 104.94 & 120.11 & 0.02 \\
\hline & ENSO & 1976 & mean & 116.04 & 120.42 & 0.11 \\
\hline & NPGO & 1998 & trend and intercept & 137.79 & 147.12 & $0.28^{\mathrm{c}}$ \\
\hline \multirow[t]{2}{*}{ All models } & SST & 1976 & trend and intercept & 58.39 & 74.15 & $<0.01$ \\
\hline & MLD & 1987 & intercept & 230.22 & 234.25 & 0.25 \\
\hline \multirow[t]{5}{*}{ HadOCC } & CHL & 1977 & mean & -138.40 & -108.32 & $<0.01^{\mathrm{c}}$ \\
\hline & PP & 1991 & intercept & -264.06 & -235.87 & $<0.01^{\mathrm{b}, \mathrm{c}}$ \\
\hline & PHY & 1977 & mean & -211.46 & -177.59 & $<0.01^{\mathrm{c}}$ \\
\hline & $\mathrm{ZOO}$ & 1977 & mean & -339.68 & -315.70 & $<0.01$ \\
\hline & DIN & 1977 & mean & 139.52 & 175.85 & $<0.01^{\mathrm{c}}$ \\
\hline \multirow[t]{7}{*}{ DiatHadOCC } & $\mathrm{CHL}$ & 1976 & mean & -44.93 & -13.82 & $<0.01$ \\
\hline & $\mathrm{PP}$ & 1976 & mean & -216.45 & -190.71 & $<0.01^{\mathrm{c}}$ \\
\hline & PHY & 1976 & intercept & -157.13 & -155.59 & 0.53 \\
\hline & $\mathrm{ZOO}$ & 1976 & intercept & -298.90 & -297.33 & 0.59 \\
\hline & DIN & 1978 & trend and intercept & 151.10 & 202.7 & $<0.01^{\mathrm{c}}$ \\
\hline & SI & 1978 & trend and intercept & 167.04 & 230.11 & $<0.01^{\mathrm{c}}$ \\
\hline & FE & 1978 & mean & -1035.5 & -990.86 & $<0.01^{\mathrm{c}}$ \\
\hline \multirow[t]{7}{*}{ MEDUSA } & $\mathrm{CHL}$ & 1997 & intercept & -287.1 & -274.71 & 0.01 \\
\hline & PP & 1991 & intercept & -308.90 & -293.98 & $0.02^{\mathrm{c}}$ \\
\hline & PHY & 1961 & mean & -342.52 & -328.88 & $<0.01$ \\
\hline & $\mathrm{ZOO}$ & 1961 & mean & -260.89 & -243.23 & $<0.01$ \\
\hline & DIN & 1978 & trend and intercept & 157.02 & 180.64 & $<0.01^{\mathrm{c}}$ \\
\hline & SI & 1966 & trend and intercept & 201.11 & 217.83 & $0.09^{c}$ \\
\hline & $\mathrm{FE}$ & 1977 & intercept & -946.48 & -938.51 & $0.10^{\mathrm{c}}$ \\
\hline \multirow[t]{7}{*}{ PlankTOM10 } & $\mathrm{CHL}$ & 1978 & intercept & -221.06 & -214.48 & $0.24^{\mathrm{c}}$ \\
\hline & $\mathrm{PP}$ & 1991 & trend and intercept & -277.74 & -258.29 & $<0.01^{\mathrm{b}, \mathrm{c}}$ \\
\hline & PHY & 1986 & intercept & -1481.6 & -1472.22 & $0.18^{\mathrm{c}}$ \\
\hline & $\mathrm{ZOO}$ & 1988 & intercept & -1427.8 & -1414.98 & $0.16^{\mathrm{a}, \mathrm{b}, \mathrm{c}}$ \\
\hline & DIN & 1978 & trend and intercept & 48.07 & 62.65 & $0.07^{\mathrm{c}}$ \\
\hline & SI & 1987 & intercept & 233.68 & 240.68 & $0.29^{\mathrm{c}}$ \\
\hline & FE & 1983 & intercept & -960.84 & -954.91 & $0.12^{\mathrm{a}, \mathrm{c}}$ \\
\hline \multirow[t]{7}{*}{ ERSEM } & $\mathrm{CHL}$ & 1976 & mean & -162.70 & -151.07 & $0.01^{\mathrm{c}}$ \\
\hline & $\mathrm{PP}$ & 1961 & trend and intercept & -211.38 & -207.73 & $0.49^{\mathrm{b}, \mathrm{c}}$ \\
\hline & PHY & 2002 & mean & 95.40 & 101.6 & 0.04 \\
\hline & $\mathrm{ZOO}$ & 1961 & trend and intercept & 175.98 & 185.44 & $0.07^{\mathrm{c}}$ \\
\hline & DIN & 1964 & trend and intercept & 6.58 & 16.48 & $0.10^{\mathrm{c}}$ \\
\hline & SI & 1991 & intercept & 122.52 & 153.74 & $0.01^{\mathrm{c}}$ \\
\hline & $\mathrm{FE}$ & 1986 & intercept & -414.51 & -412.18 & $0.57^{\mathrm{c}}$ \\
\hline
\end{tabular}

a Residuals not normally distributed (Lilliefors test, $5 \%$ critical level). ${ }^{\mathrm{b}}$ Residual variance not constant (Fisher test, $5 \%$ critical level). ${ }^{\mathrm{c}}$ Residuals not independent (Durbin-Watson test, $5 \%$ critical level): the Monte Carlo simulations to estimate the $p$ value incorporates the first-order autocorrelation of the residuals. 


\section{The Supplement related to this article is available online at doi:10.5194/bg-13-4533-2016-supplement.}

Acknowledgements. This work was funded by the UK Natural Environmental Research Council Integrated Marine Biogeochemical Modelling Network to Support UK Earth System Research (iMarNet) project (NE/K0011345/1). CB also acknowledges financial support from a Marie Curie Career Integration Grant (project 631466 - TROPHYZ). We acknowledge use of the MONSooN system, a collaborative facility supplied under the Joint Weather and Climate Research Programme, a strategic partnership between the Met Office and the Natural Environment Research Council. The authors would like to thank Clare Enright for providing model runs. The authors would also like to thank Matthew Spencer, Adrian Martin and Ryan Rykaczewski for useful comments on an earlier version of the manuscript, as well as three anonymous reviewers for constructive comments that improved the manuscript substantially.

Edited by: F. Chai

Reviewed by: three anonymous referees

\section{References}

Alexander, M., Capotondi, A., Miller, A., Chai, F., Brodeur, R., and Deser, C.: Decadal variability in the northeast Pacific in a physical-ecosystem model: Role of mixed layer depth and trophic interactions, J. Geophys. Res., 113, C02017, doi:10.1029/2007JC004359, 2008.

Alheit, J. P., Licandro, S., Coombs, A., Garcia, A., Giráldez, A., Garcia Santamaría, M. T., Slotte, A., and Tsikliras, A. C.: Atlantic Multidecadal Oscillation (AMO) modulates dynamics of small pelagic fishes and ecosystem regime shifts in the eastern North and Central Atlantic, J. Mar. Syst., 131, 21-35, 2014.

Allen, J. I., Aiken, J., Anderson, T. R., Buitenhuis, E., Cornell, S., Geider, R., Haines, K., Hirata, T., Holt, J., Le Quéré, C., Hardman-Mountford, N., Ross, O. N., Sinha, B., and While, J.: Marine ecosystem models for earth systems applications: The MarQUEST experience, J. Mar. Syst., 81, 19-33, 2010.

Andersen, T., Carstensen, J., Hernandez-Garcia, E., and Duarte, D. M.: Ecological thresholds and regime shifts: approaches to identification, Trends Ecol. Evol., 24, 49-57, 2009.

Anderson, P. J. and Piatt, J. F.: Community reorganization of the Gulf of Alaska following ocean climate regime shift, Mar. Ecol.Prog. Ser., 189, 117-123, 1999.

Baretta, J.W., Ebenhoh, W., and Ruardij, P.: The European Regional Seas Ecosystem Model, a complex marine ecosystem model, Netherlands J. Sea Res., 33, 233-246, 1995.

Beaugrand, G.: The North Sea regime shift: evidence, causes, mechanisms and consequences, Prog. Oceanogr., 60, 245-262, 2004.

Beaugrand, G., Luczak, C., and Edwards, M.: Rapid biogeographical plankton shifts in the North Atlantic Ocean, Glob. Change Biol., 15, 1790-1803, 2009.

Beaulieu, C., Chen, J., and Sarmiento, J. L.: Change-point analysis as a tool to detect abrupt climate variations, Philos. T. R. Soc. A, 370, 1228-1249, 2012.
Beaulieu, C., Henson, S. A., Sarmiento, J. L., Dunne, J. P., Doney, S. C., Rykaczewski, R. R., and Bopp, L.: Factors challenging our ability to detect long-term trends in ocean chlorophyll, Biogeosciences, 10, 2711-2724, doi:10.5194/bg-10-2711-2013, 2013.

Bellwood, D. R., Hugues, T. P., Folke, C., and Nyström, M.: Confronting the coral reef crisis, Nature, 429, 827-833, 2004.

Benson, A. J. and Trites, A. W.: Ecological effects of regime shifts in the Bering Sea and eastern North Pacific Ocean, Fish Fish., 3, 95-113, 2002.

Bestelmeyer, B. T., Ellison, A. M., Fraser, W. R., Gorman, K. B., Holbrook, S. J., Laney, C. M., Ohman, M. D., Peters, D. P. C., Pillsbury, F. C., Rassweiler, A., Schmitt, R. J., and Sharma, S.: Analysis of abrupt transitions in ecological systems, Ecosphere, 2, 129, doi:10.1890/ES11-00216.1, 2011.

Blackford, J. C.: An analysis of benthic biological dynamics in a North Sea ecosystem model, J. Sea Res., 38, 213-230, 1997.

Blackford, J. C., Allen, J. I., and Gilbert, F. J.: Ecosystem dynamics at six contrasting sites: a generic modelling study, J. Mar. Syst., 52, 191-215, 2004.

Bond, N. A., Overland, J. E., Spillane, M., and Stabeno, P.: Recent shifts in the state of the North Pacific, Geophys. Res. Lett., 30, 2183, doi:10.1029/2003GL018597, 2003.

Boulton, C. A. and Lenton, T. M.: Slowing down of North Pacific climate variability and its implications for abrupt ecosystem change, P. Natl. Acad. Sci. USA, 112, 11496-11501, 2015.

Brodeur, R. D. and Ware, D. M.: Long-term variability in zooplankton biomass in the subarctic Pacific Ocean, Fish. Oceanogr., 1, 32-38, 1992.

Buitenhuis, E., Hashioka, T., and Le Quéré, C.: Combined constraints on global ocean primary production using observations and models, Global Biogeochem. Cy., 27, 847-858, 2013.

Butenschön, M., Clark, J., Aldridge, J. N., Allen, J. I., Artioli, Y., Blackford, J., Bruggeman, J., Cazenave, P., Ciavatta, S., Kay, S., Lessin, G., van Leeuwen, S., van der Molen, J., de Mora, L., Polimene, L., Sailley, S., Stephens, N., and Torres, R.: ERSEM 15.06: a generic model for marine biogeochemistry and the ecosystem dynamics of the lower trophic levels, Geosci. Model Dev., 9, 1293-1339, doi:10.5194/gmd-9-1293-2016, 2016.

Capotondi, A., Alexander, M. A., Deser, C., and Miller, A. J.: Low frequency pycnocline variability in the northeast Pacific, J. Phys. Oceanogr., 35, 1403-1420, 2005.

Chai, F., Dugdale, R. C., Peng, T.-H., Wilkerson, F. P., and Barber, R. T.: One-dimensional ecosystem model of the equatorial Pacific upwelling system: part I, Model development and silicon and nitrogen cycle, Deep-Sea Res. Pt. II, 49, 2713-2745, 2002.

Cury, P. and Shannon, L.: Regime shifts in upwelling ecosystems: observed changes and possible mechanisms in the northern and southern Benguela, Prog. Oceanogr., 60, 223-243, 2004.

Daskalov, G. M., Grishin, A. N., Rodionov, S., and Mihneva, V.: Trophic cascades triggered by overfishing reveal possible mechanisms of ecosystem regime shifts, P. Natl. Acad. Sci. USA, 104, 10518-10523, 2007.

Denman, K. L. and Peña, M.A.: A coupled 1-D biological/physical model of the northeast subarctic Pacific Ocean with iron limitation, Deep-Sea Res. Pt. II, 46, 2877-2908, 1999.

deYoung, B., Barange, M., Beaugrand, G., Harris, R., Perry, R. I., Scheffer, M., and Werner, F.: Regime shifts in marine ecosystems: detection, prediction and management, Trends Ecol. Evol., 23, 402-409, 2008. 
Di Lorenzo, E., Schneider, N., Cobb, K.M., Franks, P. J. S., Chhak, K., Miller, A. J., McWilliams, J. C., Bograd, S. J., Arango, H., Curchitser, E., Powell, T. M., and Rivière, P.: North Pacific Gyre Oscillation links ocean climate and ecosystem change, Geophys. Res. Lett., 35, L08607, doi:10.1029/2007GL032838, 2008.

Di Lorenzo, E. and Ohman, M. D.: A double-integration hypothesis to explain ocean ecosystem response to climate forcing, P. Natl. Acad. Sci. USA, 110, 2496-2499, 2013.

Drinkwater, K. F.: The regime shift of the 1920s and 1930s in the North Atlantic, Prog. Oceanogr., 68, 134-151, 2006.

Folke, C., Carpenter, S., Walker, B., Scheffer, M., Elmqvist, T., Gunderson, L., and Holling, C. S.: Regime shifts, resilience, and biodiversity in ecosystem management, Annual Review of Ecology, Evolution and Systematics, 35, 557-581, 2004.

Francis, R. C., Hare, S. R., Hollowed, A. B., and Wooster, W. S.: Effects of interdecadal climate variability on the oceanic ecosystems of the NE Pacific, Fish. Oceanogr., 7, 1-21, 1998.

Friedrichs, M. A., Dusenberry, M. J., Anderson, L., Armstrong, R., Chai, F., Christian, J., Doney, S., Dunne, J., Fujii, M., Hood, R., McGillicuddy, D., Moore, M., Schartau, M., Spitz, Y., and Wiggert, J.: Assessment of skill and portability in regional marine biogeochemical models: the role of multiple plankton groups, J. Geophys. Res., 112, C08001, doi:10.1029/2006JC003852, 2007.

Fulton, E. A., Smith, A. D. M., and Johnson, C. R.: Effect of complexity on marine ecosystem models, Mar. Ecol.-Prog. Ser., 253, 1-16, 2003.

Garcia, H. E., Locarnini, R. A., Boyer, T. P., Antonov, J. I., Baranova, O. K., Zweng, M. M., and Johnson, D. R.: World Ocean Atlas 2009, Volume 3: Dissolved Oxygen, Apparent Oxygen Utilization, and Oxygen Saturation (ed Levitus S), 344 pp., NOAA Atlas NESDIS 70, US Government Printing Office, Washington DC, 2009a.

Garcia, H. E., Locarnini, R. A., Boyer, T. P., Antonov, J. I., Baranova, O. K., Zweng, M. M., and Johnson, D. R.: World Ocean Atlas 2009, Volume 4: Nutrients (Phosphate, Nitrate, Silicate) (ed Levitus S), 398 pp., NOAA Atlas NESDIS 71, US Government Printing Office, Washington DC, 2009b.

Haigh, S. P., Denman, K. L., and Hsieh, W. W.: Simulation of the planktonic ecosystem response to pre- and post- 1976 forcing in an isopycnic model of the North Pacific, Can. J. Fish. Aquat. Sci., 58, 703-722, 2001

Halloran, P. R., Bell, T. G., and Totterdell, I. J.: Can we trust empirical marine DMS parameterisations within projections of future climate?, Biogeosciences, 7, 1645-1656, doi:10.5194/bg-71645-2010, 2010.

Hare, S. and Mantua, N. J.: Empirical evidence for North Pacific regime shifts in 1977 and 1989, Prog. Oceanogr., 47, 103-145, 2000.

Hsieh, C.-H. and Ohman, M. D.: Biological responses to environmental forcing: the linear tracking window hypothesis, Ecology, 87, 1932-1938, 2006.

Hunke, E. C. and Lipscomb, W. H.: CICE: The Los Alamos Sea Ice Model, Documentation and Software User's Manual, Version 4.0, Los Alamos National Laboratory Tech. Rep. LA-CC06, 2008.

Kelly, R. P., Erickson, A. L., Mease, L.A., Battista, W., Kittinger, J. N., and Fujitta, R.: Embracing thresholds for better environmental management, Philos. T. R. Soc. B, 370, 20130276, doi:10.1098/rstb.2013.0276, 2015.
Key, R. M., Kozyr, A., Sabine, C. L., Lee, K., Wanningkhof, R., Bullister, J. L., Feely, R. A., Millero, F. J., Mordy, C., and Peng, T.-H.: A global ocean carbon climatology: results from Global Data Analysis Project (GLODAP), Global Biogeochem. Cy., 18, GB4031, doi:10.1029/2004GB002247, 2004.

Kwiatkowski, L., Yool, A., Allen, J. I., Anderson, T. R., Barciela, R., Buitenhuis, E. T., Butenschön, M., Enright, C., Halloran, P R., Le Quéré, C., de Mora, L., Racault, M.-F., Sinha, B., Totterdell, I. J., and Cox, P. M.: iMarNet: an ocean biogeochemistry model intercomparison project within a common physical ocean modelling framework, Biogeosciences, 11, 7291-7304, doi:10.5194/bg-11-7291-2014, 2014.

Large, W. and Yeager, S.: The global climatology of an interannually varying air-sea flux data set, Clim. Dynam., 33, 341-364, 2009.

Lees, K., Pitois, S., Scott, C., Frid, C., and Mackinson, S.: Characterizing regime shifts in the marine environment, Fish Fish., 7, 104-127, 2006.

Le Quéré, C., Harrison, S. P., Prentice, I. C., Buitenhuis, E. T., Aumont, O., Bopp, L., Claustre, H., Da Cunha, L. C., Geider, R., Giraud, X., Klaas, C., Kohfeld, K. E., Legendre, L., Manizza, M., Platt, T., Rivkin, R. B., Sathyendranath, S., Uitz, J., Watson, A. J., and Wolf-Gladrow, D.: Ecosystem dynamics based on plankton functional types for global ocean biogeochemistry models, Glob. Change Biol., 11, 2016-2040, 2005.

Lindegren, M., Blenckner, T., and Stenseth, N. C.: Nutrient reduction and climate change cause a potential shift from pelagic to benthic pathways in a eutrophic marine ecosystem, Glob. Change Biol., 18, 3491-3503, 2012.

Litzow, M. A. and Mueter, F. J.: Assessing the ecological importance of climate regime shifts: An approach from the North Pacific Ocean, Prog. Oceanogr., 120, 110-119, 2014.

Litzow, M. A., Mueter, F. J., and Hobday, A. J.: Reassessing regime shifts in the North Pacific: incremental climate change and commercial fishing are necessary for explaining decadal-scale biological variability, Glob. Change Biol., 20, 38-50, 2014.

Madec, G.: NEMO Reference Manual, Ocean Dynamic Component: NEMO-OPA, Note du Pôle de modélisation, Technical Report 27, Institut Pierre Simon Laplace, France, ISSN No. 12881619, 2008.

Mantua, N. J., Hare, S. R., Zhang, Y., Wallace, J. M., and Francis, R. C.: A Pacific interdecadal climate oscillation with impacts on salmon production, B. Am. Meteorol. Soc., 78, 1069-1079, 1997.

McGowan, J. A., Cayan, D. R., and Dorman, L. M.: Climate-ocean variability and ecosystem response in the Northeast Pacific, Science, 281, 210-217, 1998.

McQuatters-Gollop, A., Raitsos, D. E., Edwards, M., Pradhan, Y., Mee, L. D., Lavender, S. J., and Attrill, M. J.: A longterm chlorophyll data set reveals regime shift in North Sea phytoplankton biomass unconnected to nutrient trends, Limnol. Oceanogr., 52, 635-648, 2007.

Möllmann, C., Diekmann, C., Müller-Karulis, B., Kornilovs, G., Plikshs, M., and Axe, P.: Reorganization of a large marine ecosystem due to atmospheric and anthropogenic pressure: a discontinuous regime shift in the Central Baltic Sea, Glob. Change Biol., 15, 1377-1393, 2009. 
Newman, M., Compo, G. P., and Alexander, M. A.: ENSO-Forced Variability of the Pacific Decadal Oscillation, J. Climate, 16, 3853-3857, 2003.

Overland, J., Alheit, J., Bakun, A., Hurrell, J. H., Mackas, D. L., and Miller, A. J.: Climate controls on marine ecosystems and fish populations, J. Mar. Syst., 79, 305-315, 2010.

Overland, J., Rodionov, S., Minobe, S., and Bond, N.: North Pacific regime shifts: Definitions, issues and recent transitions, Prog. Oceanogr., 77, 92-102, 2008.

Page, E. S.: Continuous Inspection Scheme, Biometrika, 41, 100115,1954

Palmer, J. and Totterdell, I.: Production and export in a global ocean ecosystem model, Deep-Sea Res. Pt. I, 48, 1169-1198, 2001.

Paternoster, R., Brame, R., Mazerolle, P., and Piquero, A.: Using the correct statistical test for the equality of regression coefficients, Criminology, 36, 859-866, 1998.

Polovina, J. J., Mitchum, G. T., and Evans, G. T.: Decadal and basinscale variation in mixed layer depth and the impact on biological production in the Central and North Pacific, 1960-88, Deep-Sea Res. Pt. I, 42, 1701-1716, 1995.

Reid, P. C., Borges, M. F., and Svendsen, E.: A regime shift in the North Sea circa 1988 linked to changes in the North Sea horse mackerel fishery, Fish. Res., 50, 163-171, 2001.

Rodionov, S. N.: A sequential algorithm for testing climate regime shifts, Geophys. Res. Lett., 31, L09204, doi:10.1029/2004GL019448, 2004.

Rudnick, D. L. and Davis, R. E.: Red noise and regime shifts, DeepSea Res. Pt. I, 50, 691-699, 2003.

Scheffer, M., Bascompte, J., Brock, W., Brovkin, V., Carpenter, S. R., Dakos, V., Held, H., van Nes, E. H., Rietkerk, M., and Sugihara, G.: Early-warning signals for critical transitions, Nature, 461, 53-59, 2009.

Schwing, F. B.: Regime Shifts, Physical Forcing, in Encyclopedia of Ocean Sciences (Second Edition), edited by: Steele, J. H., 709716, Academic Press, Oxford, 2009.
Smith, T. M. and Reynolds, R. W.: Extended reconstruction of global sea surface temperatures based on COADS data (18541997), J. Climate, 16, 1495-1510, 2003.

Smith, T. M., Reynolds, R. W., Peterson, T. C., and Lawrimore, J.: Improvements to NOAA's Historical Merged Land-Ocean Surface Temperature Analysis (1880-2006), J. Climate, 21, 2283 2296, 2008.

Spencer, M., Birchenough, S. N. R., Mieszkowska, N., Robinson, L. A., Simpson, S. D., Burrows, M. T., Capasso, E., CleallHarding, P., Crummy, J., Duck, C., Eloire, D., Frost, M., Hall, A. J., Hawkins, S. J., Johns, D. G., Sims, T. D., Smyth, T. J., and Frid, C. L. J.: Temporal change in UK marine communities: trends or regime shifts?, Mar. Ecol., 32, 10-24, 2011.

Wolter, K. and Timlin, M. S.: Measuring the strength of ENSO events - how does 1997/98 rank?, Weather, 53, 315-324, 1998.

Wunsch, C.: The interpretation of short climate records, with comments on the North Atlantic and Southern Oscillations, B. Am. Meteorol. Soc., 80, 245-255, 1999.

Yatsu, A., Aydin, K. Y., King, J. R., McFarlana, G. A., Chiba, S., Tadokoro, K., Kaeriyama, M., and Watanabe, Y.: Elucidating dynamic responses of North Pacific fish populations to climatic forcing: Influence of life-history strategy, Prog. Oceanogr., 77, 252-268, 2008.

Yool, A., Popova, E. E., and Anderson, T. R.: Medusa-1.0: a new intermediate complexity plankton ecosystem model for the global domain, Geosci. Model Dev., 4, 381-417, doi:10.5194/gmd-4381-2011, 2011.

Yool, A., Popova, E. E., and Anderson, T. R.: MEDUSA-2.0: an intermediate complexity biogeochemical model of the marine carbon cycle for climate change and ocean acidification studies, Geosci. Model Dev., 6, 1767-1811, doi:10.5194/gmd-6-17672013, 2013. 